\title{
New temperature and pressure retrieval algorithm for high-resolution infrared solar occultation spectroscopy: analysis and validation against ACE-FTS and COSMIC
}

\author{
Kevin S. Olsen ${ }^{1}$, Geoffrey C. Toon ${ }^{2}$, Chris D. Boone ${ }^{3}$, and Kimberly Strong ${ }^{1}$ \\ ${ }^{1}$ Department of Physics, University of Toronto, Toronto, Ontario, Canada \\ ${ }^{2}$ Jet Propulsion Laboratory, California Institute of Technology, Pasadena, California, USA \\ ${ }^{3}$ Department of Chemistry, University of Waterloo, Waterloo, Ontario, Canada
}

Correspondence to: Kevin S. Olsen (ksolsen@atmosp.physics.utoronto.ca)

Received: 7 August 2015 - Published in Atmos. Meas. Tech. Discuss.: 23 October 2015

Revised: 11 February 2016 - Accepted: 18 February 2016 - Published: 15 March 2016

\begin{abstract}
Motivated by the initial selection of a highresolution solar occultation Fourier transform spectrometer (FTS) to fly to Mars on the ExoMars Trace Gas Orbiter, we have been developing algorithms for retrieving volume mixing ratio vertical profiles of trace gases, the primary component of which is a new algorithm and software for retrieving vertical profiles of temperature and pressure from the spectra. In contrast to Earth-observing instruments, which can rely on accurate meteorological models, a priori information, and spacecraft position, Mars retrievals require a method with minimal reliance on such data. The temperature and pressure retrieval algorithms developed for this work were evaluated using Earth-observing spectra from the Atmospheric Chemistry Experiment (ACE) FTS, a solar occultation instrument in orbit since 2003, and the basis for the instrument selected for a Mars mission. ACE-FTS makes multiple measurements during an occultation, separated in altitude by $1.5-5 \mathrm{~km}$, and we analyse $10 \mathrm{CO}_{2}$ vibration-rotation bands at each altitude, each with a different usable altitude range. We describe the algorithms and present results of their application and their comparison to the ACE-FTS data products. The Constellation Observing System for Meteorology, Ionosphere, and Climate (COSMIC) provides vertical profiles of temperature up to $40 \mathrm{~km}$ with high vertical resolution. Using six satellites and GPS radio occultation, COSMIC's data product has excellent temporal and spatial coverage, allowing us to find coincident measurements with ACE with very tight criteria: less than $1.5 \mathrm{~h}$ and $150 \mathrm{~km}$. We present an intercomparison of temperature profiles retrieved from ACE-FTS using our
\end{abstract}

algorithm, that of the ACE Science Team (v3.5), and from COSMIC. When our retrievals are compared to ACE-FTS $\mathrm{v} 3.5$, we find mean differences between -5 and $+2 \mathrm{~K}$ and that our retrieved profiles have no seasonal or zonal biases but do have a warm bias in the stratosphere and a cold bias in the mesosphere. When compared to COSMIC, we do not observe a warm/cool bias and mean differences are between -4 and $+1 \mathrm{~K}$. COSMIC comparisons are restricted to below $40 \mathrm{~km}$, where our retrievals have the best agreement with ACE-FTS v3.5. When comparing ACE-FTS v3.5 to COSMIC we observe a cold bias in COSMIC of $0.5 \mathrm{~K}$, and mean differences are between -0.9 and $+0.6 \mathrm{~K}$.

\section{Introduction}

Methane has recently been confirmed in the atmosphere of Mars by Curiosity's Tunable Laser Spectrometer on the Sample Analysis at Mars suite (Webster et al., 2015). Thought to have a short lifetime of only hundreds of years (Summers et al., 2002; Wong et al., 2003), this result suggests that Mars is either geologically or biogenically active, hosting a production mechanism for methane. Understanding such a process will impart insight into whether Mars is currently, or has been, habitable. On Earth, methane is mainly produced biologically (Atreya et al., 2007), but on Mars several geologic and exogenic sources have been suggested (e.g. Webster et al., 2015, and references therein). The discovery of methane was originally published over a decade ago by three 
independent groups: Formisano et al. (2004), Krasnopolsky et al. (2004), and Mumma et al. (2009). Their results were met with criticism (Lefèvre and Forget, 2009; Zahnle et al., 2011) and further null detection (Krasnopolsky, 2012; Webster et al., 2013) but also supporting evidence (Geminale et al., 2011; Fonti and Marzo, 2010).

To date, observations of trace gases in the Martian atmosphere have only been made by orbital instruments with limited capability, in situ landers, and Earth-based observatories, limiting results to a detection or confirmation. To understand any active processes on Mars, we need to further characterize atmospheric methane and other trace gases. We require definitive detection of trace gases, long-term global measurements to understand temporal and spatial variability and to quantify their lifetimes, sensitivity to isotopic ratios to estimate sources, and vertical profiles to probe transport. These criteria can all be addressed by an orbital Fourier transform spectrometer (FTS) with a long enough optical path difference to resolve individual spectral lines, allowing identification of trace gases and their isotopologues even in the presence of interfering molecules.

The Mars Atmospheric Trace Molecule Occultation Spectrometer (MATMOS) was an instrument jointly led by the Canadian Space Agency (CSA) and Jet Propulsion Laboratory (JPL) to send a high-resolution FTS to Mars onboard the ExoMars Trace Gas Orbiter (TGO). MATMOS was withdrawn after NASA terminated participation in the ExoMars program in 2013. The instrument was based on the CSA's Atmospheric Chemistry Experiment (ACE) FTS on SCISAT (Bernath et al., 2005) and the interferometer, metrology subsystem, and imager were to be built by ABB Bomem (an engineering demonstration unit was delivered), while the telescope, detector optics, radiative cryocooler, analog and digital electronics, thermal sub-systems, and on-board processing computer were to be provided by JPL. MATMOS and ACE-FTS operate in solar occultation mode, making measurements over a range of tangent altitudes at sunrise and sunset along the atmospheric limb. The high spectral resolution of the interferometer and the high signal-to-noise ratio and long path length of the solar occultation technique make the instruments well suited for detecting and measuring trace gases. The primary drawback of this method is its limited spatial coverage. MATMOS was designed to be capable of detecting a broad suite of trace gases in the Martian atmosphere, some with a detection capability 3 orders of magnitude greater than previously achieved.

The MATMOS and ACE-FTS interferometers feature a double-pass swing-arm optical layout with a $\pm 25 \mathrm{~cm}$ maximum optical path difference $\left(0.02 \mathrm{~cm}^{-1}\right.$ spectral resolution). There are two detectors, $\mathrm{HgCdTe}$ and InSb, with a combined spectral range of $750-4400 \mathrm{~cm}^{-1}$ for ACE-FTS and $850-4300 \mathrm{~cm}^{-1}$ for MATMOS. By comparison, the Planetary Fourier Spectrometer (PFS) on Mars Express (MEX) has a spectral range of $220-8190 \mathrm{~cm}^{-1}$ and resolution of $1.3 \mathrm{~cm}^{-1}$ (Formisano et al., 2004), while the Thermal In-
fraRed V-shape Interferometer Mounting (TIRVIM), part of the Atmospheric Chemistry Suite replacing MATMOS on TGO, will have a spectral range of $590-5880 \mathrm{~cm}^{-1}$ and solar occultation mode resolution of $0.2 \mathrm{~cm}^{-1}$ (Korablev et al., 2014).

\subsection{Observations of the Martian atmosphere}

The temperature and pressure of the Martian atmosphere have been continuously monitored by instruments on orbiting spacecraft since 1999 (Hinson et al., 2004; Forget et al., 2009; Kleinböhl et al., 2009), as have been the properties and effects of aerosols (Clancy et al., 2003; Heavens et al., 2011; Määttänen et al., 2013). The composition of the Martian atmosphere was measured by the Viking missions and Owen et al. (1977) reported $\mathrm{CO}_{2}, \mathrm{~N}_{2}, \mathrm{Ar}, \mathrm{O}_{2}, \mathrm{CO}, \mathrm{Ne}, \mathrm{Kr}$, and $\mathrm{Xe}$. The abundances of many of these gases were not updated until the arrival of the Curiosity rover, which measured $\mathrm{CO}_{2}$, $\mathrm{N}_{2}, \mathrm{Ar}, \mathrm{O}_{2}, \mathrm{CO}$, and $\mathrm{N}_{2}$ (Mahaffy et al., 2013). Other trace gases have been sought from Earth and spacecraft, but few have been discovered or confirmed, and the vertical structure of even fewer is known.

Vertical profiles of gas abundances have only been measured for $\mathrm{CO}_{2}$ (Fedorova et al., 2009), $\mathrm{O}_{3}$ (Lebonnois et al., 2006), and $\mathrm{H}_{2} \mathrm{O}$ (Maltagliati et al., 2011, 2013). The Herschel Space Observatory has been used to attempt to measure vertical profiles of $\mathrm{O}_{2}$ and $\mathrm{CO}$ (Hartogh et al., 2010a, b), but currently only spectra and vertical profiles of temperature have been published, which have both been inferred from airglow measurements made on Earth (Krasnopolsky, 2007). $\mathrm{CO}$ has been studied using spacecraft data (e.g. Sindoni et al., 2011), while $\mathrm{O}_{2}$ airglow has recently been confirmed from observations by MEX and the Mars Reconnaissance Orbiter (MRO) (Bertaux et al., 2012; Clancy et al., 2012). NO has also been inferred from airglow measurements from MEX (Bertaux et al., 2005; Gagné et al., 2013). The existence of $\mathrm{O}_{2}$ and NO in the upper atmosphere imply complex photochemistry (e.g. Atreya et al., 2007; Barth et al., 1992), but several predicted molecules, including $\mathrm{N}_{2} \mathrm{O}, \mathrm{NO}_{2}$, and $\mathrm{HO}_{2}$, have not been observed (Villanueva et al., 2013, and references therein).

Conversely, $\mathrm{H}_{2} \mathrm{O}_{2}$ has been discovered, first from Earth (Clancy et al., 2004; Encrenaz et al., 2012) and recently confirmed by MEX data (Aoki et al., 2015). $\mathrm{H}_{2}$ has been observed from Earth (Krasnopolsky and Feldman, 2001), which suggests that the radical $\mathrm{OH}$ should also be present, which was also recently confirmed by MRO observations (Clancy et al., 2013). Searches are ongoing, without a detection, for sulphur species such as $\mathrm{SO}_{2}$ (Encrenaz et al., 2011; Krasnopolsky, 2012), indicative of volcanic activity, and chlorine species such as $\mathrm{HCl}$ (Villanueva et al., 2013), which is suggested by the discovery of perchlorates on the surface (Hecht et al., 2009; Glavin et al., 2013).

A MATMOS-like instrument would be capable of setting detection limits of $\mathrm{N}_{2} \mathrm{O}, \mathrm{NO}_{2}, \mathrm{HO}_{2}, \mathrm{HCl}, \mathrm{SO}_{2}, \mathrm{OCS}$, and 
other organic molecules between 1 and $50 \mathrm{ppt}$. In dust-free conditions, the sensitivity of MATMOS would be $<10 \mathrm{ppt}$ for most infrared-active target gases.

\subsection{Solar occultation retrievals}

Retrieving trace gas abundances from solar occultation spectra is done by fitting a computed spectrum to the measured data. A single occultation sequence generates a set of spectra at different tangent altitudes, and all are fit simultaneously. Achieving a good fit requires properly modelling the shape of each line (using physical and spectroscopic parameters), accounting for background and interfering components, and having the correct line depth, which depends on the amount of the absorber at various sampled altitudes. Retrievals at Mars are more difficult than at Earth for several reasons:

- the lack of meteorological analyses;

- the lack of communication infrastructure to determine spacecraft location;

- colder atmospheric temperatures, which increase the sensitivity to errors, and for which $\mathrm{CO}_{2}$ self-broadening parameters need to be determined;

- seasonal variations in surface pressure caused by the $\mathrm{CO}_{2}$ ice cycles at the poles;

- weak pressure broadening in the thin atmosphere;

- the prospect of high levels of stratified suspended dust, which attenuates solar radiation, has broad spectral features at all wavelengths and has varying opacity during the acquisition of a single spectrum, distorting the shape of spectral lines.

The retrieval strategy commonly used is to determine and fix as many parameters as possible prior to fitting the spectra since the system may be underdetermined if insufficient a priori information is provided to ensure a unique solution. Predetermining parameters is further advantageous since gas absorption coefficients depend on temperature and pressure. However, $T, P$, and altitude are interdependent and must be restricted by the equation of hydrostatic equilibrium. The MATMOS team selected the GGG software suite (Goldman et al., 1999), maintained at JPL, for performing retrievals. GGG grew out of software developed for the Atmospheric Trace Molecule Spectroscopy (ATMOS) Space Shuttle mission (Norton, 1991) (using an onion-peeling scheme) and was used by Irion et al. (2002) for the final version of analysis of ATMOS spectra (using the global-fitting approach of Carlotti, 1988). GGG is now used by the Total Carbon Column Observing Network (TCCON) (Wunch et al., 2011) and MkIV balloon program (Toon, 1991) (using a limited optimal estimation scheme for each spectrum described in Wunch et al., 2011). The ACE-FTS retrieval software, described in Sect. 2.1, relies on a combination of assumptions, a priori knowledge, and data from models. Operating at another planet, these a priori profiles are unknown and models of the Mars atmosphere have not been developed to a suitable level for this purpose. Our objective is to develop a method for pressure and temperature retrievals with minimal reliance on such assumptions. The practical advantages of developing a new method are that it will be integrated into GGG, which has already been adapted for Mars, while the ACE method is highly specific to Earth observations and the ACE-FTS instrument and may be challenging to adapt without key personnel on the ACE team.

Our method, described in Sect. 2.3, exploits the temperature dependence of individual absorption lines in vibrationrotation bands of $\mathrm{CO}_{2}$. Spectral fitting is done over microwindows containing $\mathrm{CO}_{2}$ absorption lines with different ground state energies by varying the $\mathrm{CO}_{2}$ volume mixing ratio (VMR). This method requires a priori $\mathrm{CO}_{2}$ VMRs, $T$, and $P$, and its sensitivity to the a priori profiles is discussed in Sect. 3.1. The fitting results for all windows encompassing a band are analysed to deduce temperature and pressure. This technique is based on early ATMOS retrievals (Stiller et al., 1995) but benefits from the broader simultaneous spectral range of ACE-FTS and MATMOS (allowing us to use more $\mathrm{CO}_{2}$ bands and retrieve over the full altitude range) and advancements made to GGG (e.g. updated spectral parameters, line lists, and line shapes, but especially the ability to fit multiple gases in a window simultaneously and no longer relying on onion peeling). We use a different mathematical treatment, a new scheme for determining a pressure profile, and a new restriction for maintaining hydrostatic equilibrium.

After a vertical profile for $T$ and $P$ has been found, the method can be applied iteratively, using the retrieved vertical profiles as refined a priori. This was originally done by Stiller et al. (1995) for ATMOS. While there can be convergence issues with an iterative approach, as noted in Sect. 2.2, it may be used for a MATMOS-like mission. The ACE-FTS retrievals presented here were not done iteratively because of the high quality of the a priori. Iterating the retrieval too many times for ACE-FTS tended to introduce oscillations in the temperature profile, especially above $70 \mathrm{~km}$, where our assumptions break down. For Mars, where the a priori will be less accurate, iterating the temperature retrieval may be beneficial.

A set of 129 occultations recorded by ACE-FTS, representing different latitudes and seasons, were analysed; they are discussed in Sect. 3.2 and results are shown in Sect. 3.3. Each ACE-FTS occultation is a series of 30-130 (mean 53) spectra recorded at tangent altitudes between 5 and $15 \mathrm{~km}$. The Constellation Observing System for Meteorology, Ionosphere, and Climate (COSMIC) is a six-satellite constellation that uses GPS (Global Positioning System) radio occultation to obtain high-precision vertical profiles of temperature (Anthes et al., 2008). Many of the ACE-FTS occultations presented in Sect. 3.2 were chosen to be coincident with COSMIC GPS occultations, using tight coincidence criteria of $1 \mathrm{~h}$ 
and $150 \mathrm{~km}$. We use the COSMIC data product to independently validate our analysis, and an intercomparison is shown in Sect. 3.4.

\section{Retrieval technique}

\subsection{ACE-FTS pressure and temperature retrievals}

ACE-FTS retrievals are described in Boone et al. (2005) for version 2.2 (v2.2) and Boone et al. (2013) for version 3.0 (v3.0). Validation of ACE-FTS v2.2 temperature by Sica et al. (2008) revealed three issues with retrieved temperature profiles: unphysical oscillations in the mesosphere for some occultations, a systematic bias near $23 \mathrm{~km}$ related to an empirical function used to impose smooth behaviour in retrieved pressures below $23 \mathrm{~km}$ in v2.2, and a warm bias of around $3-6 \mathrm{~K}$ in the mesosphere. ACE-FTS v3.0 addresses the above issues with temperature. In October 2010, a change in the format of the outputs from the Canadian Meteorological Centre's (CMC's) analysis model introduced errors into the a priori pressure and temperature data used by the ACE-FTS retrievals, which impacted v2.2 and v3.0 results from that date onward. In ACE-FTS version 3.5 (v3.5), occultations since September 2010 have been reprocessed with the correct a priori pressure and temperature. Pointing information from SCISAT is subject to systematic timing errors, which necessitates determination of the measurement geometry from analysis of the ACE-FTS spectra. Comparisons presented here use ACE-FTS v3.5.

ACE-FTS $P / T$ retrievals are divided near $50 \mathrm{~km}$ into a high-altitude regime, up to $120 \mathrm{~km}$, and a low-altitude regime, down to $15 \mathrm{~km}$. The retrieval proceeds in two stages, beginning with the determination of a crossover pressure near $50 \mathrm{~km}$ that serves as the boundary between the highand low-altitude regions. The high-altitude retrieval is performed first and includes the tangent pressure at the crossover level as a fitting parameter. The low-altitude retrieval follows with the crossover pressure fixed. The crossover pressure is refined, and $P / T$ retrievals are repeated. The ACE-FTS retrieval follows these steps:

1. calculate high-altitude tangent altitudes from satellite position

2. estimate low-altitude tangent altitudes from $\mathrm{N}_{2}$ continuum

3. perform high-altitude $P / T$ retrieval with the crossover pressure as a fitting parameter

4. refine low-altitude tangent altitude spacing using the equation of hydrostatic equilibrium

5. perform low-altitude $P / T$ retrieval

6. refine the crossover pressure
7. repeat high-altitude $P / T$ retrieval with the crossover pressure fixed

8. repeat low-altitude $P / T$ retrieval

9. shift tangent altitudes to agree with low-altitude meteorological data.

The high- and low-altitude retrievals both determine the temperature profile by fitting a set of spectral windows containing $\mathrm{CO}_{2}$ lines with $1 / T$ as a free parameter. They differ in how they determine pressure, tangent altitude, and the $\mathrm{CO}_{2}$ VMR.

Prior to the retrieval, the crossover level between the highand low-altitude retrievals is chosen. During the first pass of the high-altitude retrieval, pressure at the crossover level is fitted along with temperature. During the first pass of the lowaltitude retrieval, a refined value for the crossover pressure is determined that yields the closest match to expectations for the highest calculated tangent altitude.

The high-altitude retrieval pre-determines tangent altitudes, pressures, and a portion of the $\mathrm{CO}_{2}$ VMR profile. In the absence of conditions that would impact the alignment of the sun tracker on the solar disk, such as clouds or significant refraction, relative pointing information can be accurately determined from knowledge of the satellite's orbital data, which are used to directly calculate tangent altitudes. Knowing the measurement geometry, the change in tangent pressure from one measurement to the next can be calculated by integrating the equation for hydrostatic equilibrium, taking into account the decrease in acceleration due to gravity with altitude and the changing average mean molecular mass. The altitude dependence of the mean molecular mass is determined from the outputs of the US Naval Research Laboratory (NRL) Mass Spectrometer and Incoherent Scatter (MSIS) radar model (NRL-MSISE-00) (Picone et al., 2002). Beginning around 60 to $90 \mathrm{~km}$, depending on the geolocation and season, $\mathrm{CO}_{2}$ concentrations fall off with increasing altitude, making the a priori $\mathrm{CO}_{2} \mathrm{VMRs}$ less reliable. The $\mathrm{CO}_{2} \mathrm{VMR}$ is fixed to the a priori between the crossover pressure level and $\sim 70 \mathrm{~km}$. Spectral fitting is then performed to determine the temperature profile with $1 / T$, the crossover pressure, and $\mathrm{CO}_{2}$ VMR above $70 \mathrm{~km}$ as parameters. An empirical function is used to describe the fitted $\mathrm{CO}_{2}$ VMR profile above $\sim 70 \mathrm{~km}$ in order to force the results to exhibit smooth behaviour.

At low altitudes, a priori knowledge of the $\mathrm{CO}_{2} \mathrm{VMR}$ profile is relatively accurate, so it is fixed. A first guess of the tangent altitudes is made using the baseline ratio in the $\mathrm{N}_{2}$ continuum level. Tangent altitudes below the crossover pressure level are determined by integrating the hydrostatic equation downward from that altitude using the results of the high-altitude retrieval. Spectral fitting over a set of microwindows containing $\mathrm{CO}_{2}$ lines is done with both pressure and temperature $(1 / T)$ as parameters. 


\subsection{Tangent altitudes}

As described in Sect. 2.1, the geometry at high altitudes is directly calculated from knowledge of the satellite's orbit, while the tangent altitudes at low altitudes are determined during the $P / T$ retrieval through integration of the equation for hydrostatic equilibrium. This process yields good relative pointing information, but to obtain absolute pointing information an altitude registration step is required. In v3.5, at the end of the $P / T$ retrieval, all tangent altitudes are shifted by a common amount in order to have the retrieved pressures between 15 and $25 \mathrm{~km}$ match the a priori pressures from the CMC. Below $15 \mathrm{~km}, P$ and $T$ are fixed to the a priori data from the $\mathrm{CMC}$, and tangent altitudes in this altitude region are fitted using a set of ${ }^{18} \mathrm{O}^{12} \mathrm{C}^{16} \mathrm{O}$ spectral lines (Boone et al., 2013).

Ideally, future iterations of an ACE-like FTS will have more reliable pointing information, allowing tangent altitudes to be determined independently of $T, P$, and gas VMRs. One method used by the MkIV balloon missions determines tangent altitudes from $\mathrm{CO}_{2}$ lines (Goldman et al., 1999). In GGG, tangent altitudes are computed geometrically from the solar zenith angle and account for effects such as refraction. Corrections to tangent altitude in GGG are made by iteratively adding pointing offsets to the solar zenith angles until the retrieved $\mathrm{CO}_{2}$ VMR profile matches the a priori. For our application, we encountered two problems: (i) the MkIV method requires very accurate a priori $\mathrm{CO}_{2}, T$, and $P$; (ii) we are using the same data to first obtain tangent altitude, then $T$ and $P$, which can iteratively be used to re-determine $z$, and so on. An iterative approach does not reduce uncertainties, can introduce unphysical oscillations, and is estimating too many unknown parameters from the same data.

Our retrievals are very sensitive to altitude (since variations in altitude are effectively variations in $T$ and $P$ ), and the MkIV method tended to yield a $0.5-1.5 \mathrm{~km}$ bias when compared to ACE-FTS retrievals. To avoid biases caused by altitude errors, we use ACE-FTS retrieved tangent altitudes instead. Ideally, a MATMOS-like mission would have better pointing information available and a more accurate altitude determination scheme. This provides a more direct comparison of temperatures retrieved here and by ACE-FTS, and we can be certain we are comparing temperatures estimated from a single spectrum at a given altitude, which becomes difficult when tangent altitude spacing is of the same order as tangent altitude uncertainty. A minimization scheme is used to determine the pointing offset that returns the ACE-FTS altitudes in GGG.

\subsection{Determining temperatures}

Rather than using $T$ and $P$ as fitting parameters, we developed a method to estimate $T$ and $P$ by analysing the results of spectral fitting using $\mathrm{CO}_{2} \mathrm{VMR}$ as the adjusted parameter. A similar technique was first demonstrated by Stiller et al.
(1995) and was used to determine temperature profiles from the ATMOS solar occultation FTS, deployed on the Space Shuttle for four missions (Irion et al., 2002). We start by fitting individual spectral lines in a $\mathrm{CO}_{2}$ vibration-rotation band. We then exploit the temperature dependence of the absorption lines by looking at systematic variations in retrieved VMR as a function of the lower energy state of each line's transition in a band. Spectral fitting is performed for all altitudes and windows first, then followed by the analysis of retrieved VMR and energy states to derive a vertical profile of $T$. The following steps are taken to retrieve vertical profiles of temperature and pressure and are explained in the following sections:

1. Spectral fitting of $\mathrm{CO}_{2}$ lines is performed for $10 \mathrm{CO}_{2}$ vibration-rotation bands with around 40 lines each.

2. Data quality criteria are imposed on resulting VMR scale factors (VSFs).

3. Temperature and pressure are computed for each band at each altitude.

4. Weighted means of $T$ and $P$ are calculated for each altitude to produce vertical profiles of $T$ and $P$.

5. At each altitude, weighted means of $T$ and $P$ are calculated to produce vertical profiles of $T$ and $P$.

6. The altitude with the highest-quality pressure retrieval is estimated.

7. The vertical profile of temperature is integrated above and below the altitude with the highest-quality pressure retrieval.

8. A vertical profile of pressure is computed using the equation of hydrostatic equilibrium.

When GGG fits a computed spectrum to a measured spectrum over a spectral window, it varies the VMR of the target gases until a best fit is achieved. The result is the VSF for each target gas at each altitude, defined for some target gas, by the following equation:

Column $=\operatorname{VSF} \int \chi^{\prime} n_{a} \mathrm{~d} s$,

where the left-hand side is the total column of the target gas along the slant path through the atmosphere, between the sun and the instrument, taking into account bending due to refraction. $\chi^{\prime}$ is the VMR of the target gas (the prime notation indicates that it is an a priori quantity), $n_{a}$ is the total number density, and $s$ is the path variable. VSF is therefore the ratio between the true total column of gas, and that calculated by GGG. In solar occultation geometry, once fitting has been performed, and if the altitude, pressure, and temperature are correct, then the slant paths of the actual column and 
the a priori column are the same. GGG divides the atmosphere into homogeneous layers, calculates the optical path for an observation, and accounts for the contributions from each layer. Therefore, the VSF is the ratio between a priori and true gas amounts averaged over the slant path, and we express the retrieved VMR as VSF $\chi^{\prime}$.

For transmission spectra, we can describe the depth of an absorption feature with the Beer-Lambert law:

$$
I(\widetilde{v})=I_{\circ}(\widetilde{v}) \exp \left[\sum_{i}-S\left(T_{i}\right) f\left(T_{i}, P_{i}, \widetilde{v}\right) \chi_{i}\left(P_{i} / k T_{i}\right) l_{i}\right],
$$

where the sum is of contributions from each layer of the atmosphere the solar ray passes through, $i$ is an atmospheric layer, $I(\widetilde{v})$ is the transmitted intensity at wave number $\widetilde{v}$, $I_{\circ}(\widetilde{v})$ is the incident intensity, $S\left(T_{i}\right)$ is the temperaturedependent line strength defined in Rothman et al. (1998), $f\left(T_{i}, P_{i}, \widetilde{v}\right)$ is the line shape function, $k$ is the Boltzmann constant, and $l_{i}$ is the optical path length. After fitting, we assume that the measured transmittance, $I(\widetilde{v}) / I_{\circ}(\widetilde{v})$, is equal to the calculated transmittance, $I^{\prime}(\widetilde{v}) / I_{\circ}^{\prime}(\widetilde{v})$, computed by GGG using a priori quantities and the VSF. We also assume that the line shape function, optical path length, and incident intensity for $I(\widetilde{v})$ and $I^{\prime}(\widetilde{v})$ are equivalent $\left(f_{i} \equiv f_{i}^{\prime}\right.$, $\left.l_{i} \equiv l_{i}^{\prime}, I_{\circ}(\widetilde{\mathcal{v}}) \equiv I_{\circ}^{\prime}(\widetilde{\mathcal{V}})\right)$. We further simplify the expression for $I(\widetilde{v})=I^{\prime}(\widetilde{v})$ by assuming GGG has already accounted for the contributions from each layer $i$ and obtain an expression for the retrieved VMR, VSF $\chi^{\prime}$, at the altitude of the observation:

$$
\mathrm{VSF}_{j} \chi_{j}^{\prime}=\frac{S\left(T_{j}\right)}{S\left(T_{j}^{\prime}\right)} \chi_{j} \frac{P_{j}}{P_{j}^{\prime}} \frac{T_{j}^{\prime}}{T_{j}},
$$

where $j$ represents the altitude of the tangent point of the optical path for an observation.

The ratio of line strengths is

$$
\frac{S(T)}{S\left(T^{\prime}\right)}=\frac{Q_{\mathrm{R}}\left(T^{\prime}\right)}{Q_{\mathrm{R}}(T)} \frac{Q_{\mathrm{V}}\left(T^{\prime}\right)}{Q_{\mathrm{V}}(T)} \frac{1-e^{-\frac{h c \widetilde{v}}{k T}}}{1-e^{-\frac{h c \tilde{v}}{k T^{\prime}}}} \frac{e^{h c E^{\prime \prime} / k T^{\prime}}}{e^{h c E^{\prime \prime} / k T}},
$$

where the lower energy state of the transition, $E^{\prime \prime}$, is expressed in $\mathrm{cm}^{-1}$, and $Q_{\mathrm{R}}(T)$ and $Q_{\mathrm{V}}(T)$ are the rotational and vibrational partition functions. The ratio of rotational partition functions can be expressed as simply $T^{\prime} / T$ for $\mathrm{CO}_{2}$ and we argue that ratio of vibrational partition functions and the ratio of spontaneous emission terms $\left(1-e^{-\frac{h c v}{k T}}\right)$ are approximately equal to 1 for the differences between $T$ and $T^{\prime}$ that we expect (on the order of 1 to $10 \mathrm{~K}$ ). GGG uses an empirical model developed for TCCON to calculate the telluric a priori $\mathrm{CO}_{2}$ profile as described in Wunch et al. (2011). We rely on the quality of the a priori $\mathrm{CO}_{2}$ VMR profiles to remove the dependence on the true $\mathrm{CO}_{2} \mathrm{VMR}, \chi$, from our equations by assuming $\chi / \chi^{\prime} \approx 1$. The a priori VMR vertical profiles for other molecules were provided by TCCON, while a priori $T, P$, and specific humidity vertical profiles up to $40 \mathrm{~km}$ were derived from National Centers for Environmental Prediction (NCEP) reanalysis data (Kalnay et al., 1996) (the US standard atmosphere was used above $40 \mathrm{~km}$ ). With these assumptions, combining Eqs. (3) and (4) yields

$\ln (\mathrm{VSF})=\ln \left(\frac{\chi}{\chi^{\prime}}\left(\frac{T^{\prime}}{T}\right)^{2} \frac{P}{P^{\prime}}\right)+\frac{h c E^{\prime \prime}}{k}\left(\frac{1}{T^{\prime}}-\frac{1}{T}\right)$.

The result is a linear relationship between $\ln (\mathrm{VSF})$ and $E^{\prime \prime}$. A set of spectral micro-windows targets individual $\mathrm{CO}_{2} \mathrm{ab}-$ sorption lines in a $\mathrm{CO}_{2}$ vibration-rotation band. Each line is fitted at each observation altitude to determine the VSF and a the linear relationship in Eq. (5) is fitted using $E^{\prime \prime}$ values reported by Rothman et al. (2013). From the slope of the best fit line, we derive $T$, and from the $y$ intercept, we derive $P$.

In this study, 10 strong $\mathrm{CO}_{2}$ bands were studied. Each band has its own effective altitude range, below which absorption may be total and above which absorption may be negligible. In some cases, interference from other molecules may hamper our $\mathrm{CO}_{2}$ line fits. The bands used, and their effective altitude ranges and interfering molecules, are listed in Table 1. Because at certain altitudes, lines in some bands may be too weak to fit reliably, each band is analysed separately. Least squares estimation is used, with each data point weighted using the propagated uncertainties returned from spectral fitting. We rely on these uncertainties to flag bad fits to VSF and, thus, which bands are unsuitable for retrieving temperature at each altitude. At a given altitude, temperature, $T$, pressure, $P$, and their uncertainties, $\delta T$ and $\delta P$, are computed for each band and then a data quality filter is applied to $T$ values from each band to determine which results to use in a weighted mean. This is followed by a data quality filter on pressure. For temperature, we require $0<\delta T / T<a$ and $\left|T-T^{\prime}\right|<25$, and pressure additionally requires $0<\delta P / P<b$, with $a$ and $b$ determined empirically and subject to change but usually $<1$. Figure 1 shows typical $\ln$ (VSF) vs. $E^{\prime \prime}$ relationships for an altitude where four bands passed the data quality filter and were used to estimate $T$, with transitions, fitting results, and uncertainties labelled. Error bars are the variance of the weighted mean.

After processing all 129 occultations, we assessed any biases between $\mathrm{CO}_{2}$ bands, incorporated corrections into our software, and compared results of reprocessing with our original results. We investigated slope, intercept, retrieved $T$, and VSF, and their relationships with altitude, season, and retrieved and a priori temperatures for each band at every altitude and occultation. Any bias between bands is very small, obscured by the spread of data, and insignificant compared to seasonal variations. For VSF, slope and $T$ we computed the exponentially weighted mean at every altitude for all the fitting data and for each band. The ratio of each band's mean to the total mean was found and interpolated onto a $1 \mathrm{~km}$ grid to be used as a bias correction. The VSF ratios for each band were between 0.8 and 1.2 and tended to diverge at higher altitudes, while those for temperature were between 0.95 and 
Table 1. List of $\mathrm{CO}_{2}$ vibration-rotation bands used in $T-P$ analysis. Each band's central wave number is given by Rothman et al. (1992) and the range is of the micro-windows used, which are predominantly between 0.2 and $0.32 \mathrm{~cm}^{-1}$. Interfering species are gases with absorption lines occupying the micro-windows, but are also fitted by GGG. The effective altitude range is that over which absorption lines are strong enough relative to noise to be fitted, but not so strong that absorption is total over the range of the micro-window, and where the micro-window is not dominated by strong absorption by interfering species.

\begin{tabular}{lrrrrr}
\hline Transition & $\begin{array}{r}\text { Central } \\
\text { wave number } \\
\left(\mathrm{cm}^{-1}\right)\end{array}$ & $\begin{array}{r}\text { Band } \\
\text { range } \\
\left(\mathrm{cm}^{-1}\right)\end{array}$ & $\begin{array}{r}\text { Windows } \\
\text { used }\end{array}$ & $\begin{array}{r}\text { Primary } \\
\text { interfering } \\
\text { species }\end{array}$ & $\begin{array}{r}\text { Effective } \\
\text { altitude } \\
\text { range }(\mathrm{km})\end{array}$ \\
\hline $00^{0} 1 \leftarrow 10^{0} 0^{1}$ & 961.0 & $920.6-984.6$ & 38 & $\mathrm{O}_{3}, \mathrm{CCL}_{2} \mathrm{~F}_{2}$ & $12-62$ \\
$00^{0} 1 \leftarrow 02^{0} 0$ & 1063.7 & $1016.5-1095.0$ & 49 & $\mathrm{O}_{3}, \mathrm{H}_{2} \mathrm{O}$ & $50-65$ \\
$03^{0} 0 \leftarrow 00^{0} 0^{1}$ & 1932.5 & $1888.7-1977.0$ & 69 & $\mathrm{H}_{2} \mathrm{O}, \mathrm{O}_{3}$ & $22-70$ \\
$11^{1} 0 \leftarrow 00^{0} 0^{1}$ & 2076.9 & $2002.3-2127.6$ & 89 & $\mathrm{O}_{3}, \mathrm{H}_{2} \mathrm{O}, \mathrm{CO}$ & $25-86$ \\
$00^{0} 0 \leftarrow 00^{0} 1^{\mathrm{a}, \mathrm{b}}$ & 2349.1 & $2303.2-2382.8$ & 53 & & $60-140$ \\
$10^{0} 1 \leftarrow 02^{0} 0^{1}$ & 2429.4 & $2396.8-2457.8$ & 41 & $\mathrm{~N}_{2} \mathrm{O}, \mathrm{CH}_{4}$ & $30-50$ \\
$15^{1} 0 \leftarrow 00^{0} 0^{1}$ & 3181.5 & $3152.7-3221.7$ & 32 & $\mathrm{O}_{3}, \mathrm{CH}_{4}, \mathrm{H}_{2} \mathrm{O}$ & $10-35$ \\
$13^{1} 0 \leftarrow 00^{0} 0^{1}$ & 3339.4 & $3298.0-3381.9$ & 50 & $\mathrm{~N}_{2} \mathrm{O}, \mathrm{H}_{2} \mathrm{O}$ & $12-60$ \\
$02^{0} 1 \leftarrow 00^{0} 0$ & 3612.8 & $3494.5-3646.4$ & 94 & $\mathrm{H}_{2} \mathrm{O}, \mathrm{N}_{2} \mathrm{O}, \mathrm{O}_{3}$ & $45-109$ \\
$10^{0} 1 \leftarrow 00^{0} 0$ & 3714.8 & $3674.3-3743.7$ & 45 & $\mathrm{H}_{2} \mathrm{O}$ & $50-109$ \\
\hline
\end{tabular}

a Lines from this band were used by Stiller et al. (1995).

${ }^{\mathrm{b}} \mathrm{CO}_{2} v_{3}$.
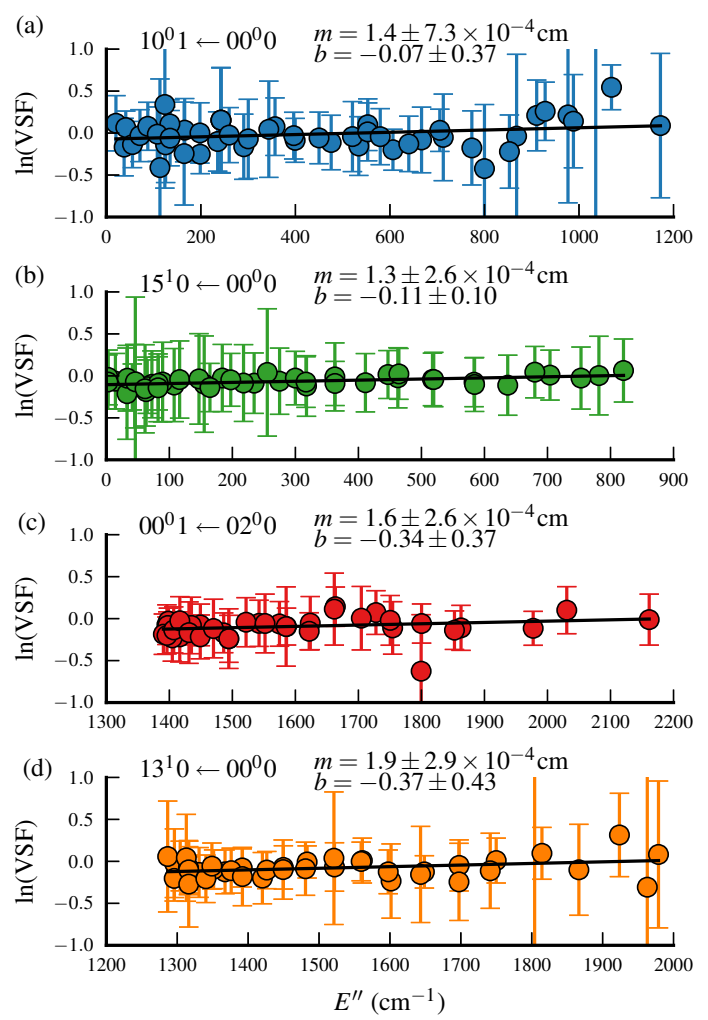

Figure 1. Example of $\ln (\mathrm{VSF})$ vs. $E^{\prime \prime}$ relationships (see Eq. (5)) for $\mathrm{CO}_{2}$ bands that passed all quality criteria and were used to retrieve $T$. The four transitions are (a) $10^{0} 1 \leftarrow 00^{0} 0$, (b) $15^{1} 0 \leftarrow 00^{0} 0$, (c) $00^{0} 1 \leftarrow 02^{0} 0$, and (d) $13^{1} 0 \leftarrow 00^{0} 0$. These are from ACE-FTS occultation ss5211 on 31 July 2004, over the Middle East, at an altitude of $38.1 \mathrm{~km}$. Labelled for each band are the transition, slope $m$, and $y$ intercept $b$ of the best fit line.
1.05. Means of slope were on the order of $10^{-3}$, leading to unstable ratios. The effect of incorporating a bias correction was negligible.

Using several $\mathrm{CO}_{2}$ bands and a statistical approach to data quality control provides a robust retrieval method capable of retrieving $T$ at all observation altitudes and for a variety of atmospheric conditions without extensive rewriting of retrieval software or highly specific retrieval procedures for a set of scenarios. Figure 2 shows vertical profiles of $T$ and $P$ retrieved using GGG compared to ACE-FTS v3.5 and the individual values retrieved from each band. This illustrates the spread of estimated $T$ and $P$ derived from different bands at each observation, the varying altitude range of the bands, and the effectiveness of the retrieval algorithm.

\subsection{Determining pressures}

Retrieving a vertical profile of pressure using Eq. (5) can give unrealistic results and large discrepancies between $\mathrm{CO}_{2}$ bands. One problem is that small errors in tangent altitude lead to large errors in pressure due to the exponential relationship between the two. Another is that varying $T, P$, and $z$ independently violates the assumption of hydrostatic equilibrium, which must constrain simultaneous retrievals of $T$ and $P$.

A vertical profile of pressure is retrieved by first determining the pressure level with the highest retrieval quality, $P_{a}$, then integrating the retrieved $T$ profile above and below this observation level and computing pressure from the equation of hydrostatic equilibrium: 

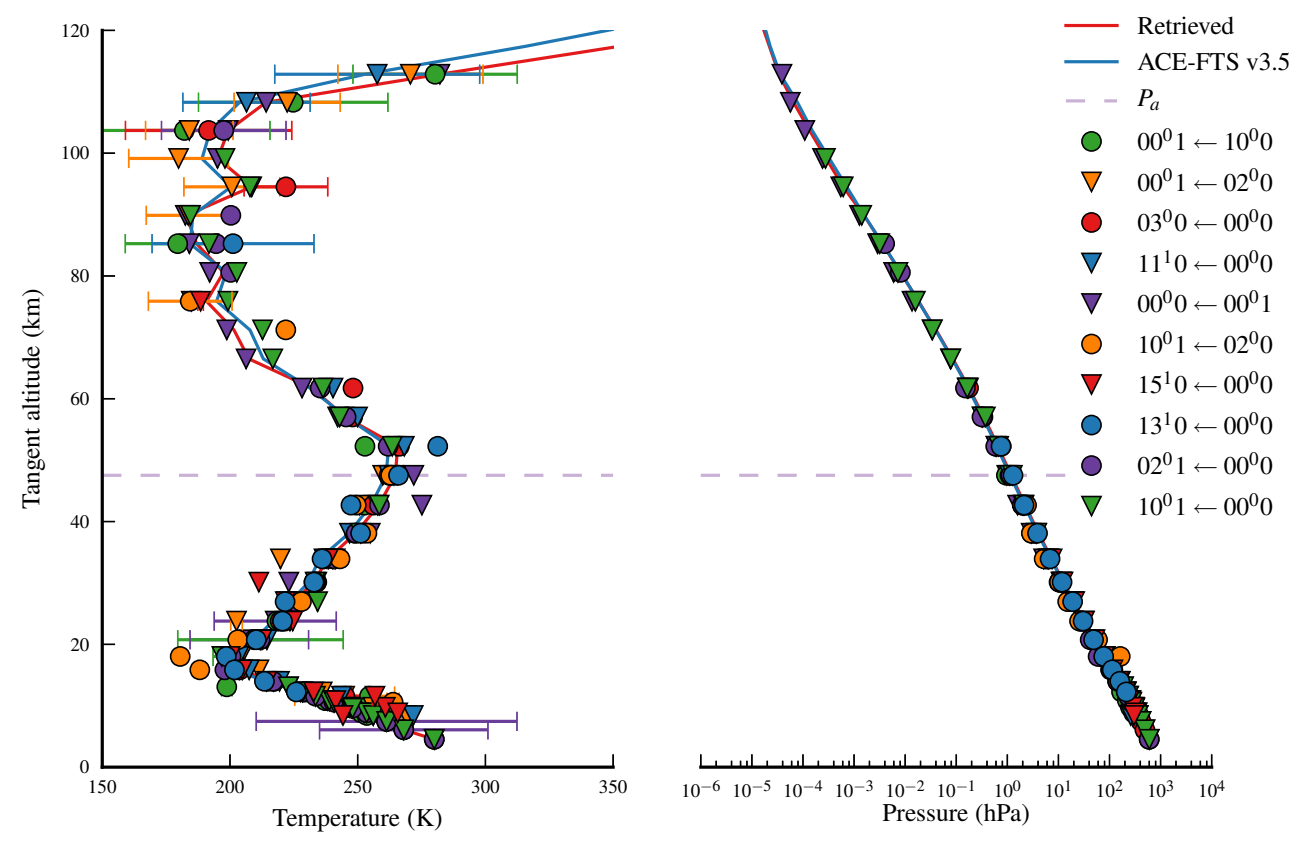

Figure 2. Retrieved $T$ and $P$ using all $\mathrm{CO}_{2}$ bands at all tangent altitudes for ACE-FTS occultation ss5211. Each marker indicates a band that passed data quality criteria; no bands contribute at every altitude. The retrieved pressure profile (red line) is that computed from Eq. (6) by integrating the retrieved temperature profile above and below $P_{a}$. The horizontal dashed line indicates the $P_{a}$ level.

$P(h)=P_{a} \exp \left(-\frac{g M}{R} \int_{a}^{h} \frac{1}{T(z)} \mathrm{d} z\right)$,

which is used to determine $P$ at a given altitude, $h$, from $P_{a}$ at altitude $a$. The acceleration due to gravity, $g$, and the mean molar mass of air, $M$, are left constant to keep the integration general and quickly adaptable to other planets. $R$ is the gas constant. $P_{a}$ is restricted to altitudes between 18 and $52 \mathrm{~km}$ where $T$ was retrieved. It is the level with the minimum standard deviations and fractional uncertainties of retrieved $T$ and $P$.

Integration in Eq. (6) is done by dividing the retrieved $T$ profile into four layers (troposphere, stratosphere, mesosphere, thermosphere) at each inversion point and fitting a fifth-order polynomial to $1 / T(z)$ in each layer. The integrals are then evaluated exactly using the fitting coefficients. This method is used because spacing in $z$ is non-uniform, there may be very large gaps in $z$ between measurements, there may be discontinuities in $T$, or the domain of $z$ may not be ordered. The latter can occur physically at low altitudes when tracking the centre of the solar disk is complicated by refraction affecting its shape or by the horizon partially obscuring it. It can also occur at any altitude if the altitude spacing is tight and there are errors in retrieved altitude. This method also relaxes the restriction that the integrated function pass through every data point by weighting them according to uncertainty.
Since $P$ is computed from the equation of hydrostatic equilibrium, as it is at higher altitudes in the ACE-FTS retrievals, there are only three factors that introduce deviations from ACE-FTS $P$, which is registered against meteorological data at low altitudes (Boone et al., 2013): pressure at the $P_{a}$ level, the $T$ profile, and using constant $M$ and $g$. Figure 3 shows the correlation between our retrieved $P_{a}$ and the $P$ used by ACE-FTS v3.5 at the same observation level for all occultations in Sect. 3.2. The slope and intercept are $0.991 \pm 0.007$ and $-0.01 \pm 0.04$ respectively and the correlation coefficient, $R^{2}$, is 0.996 . After retrieving $P$ profiles, we investigated registration of tangent altitudes using ACE-FTS $P$ profiles below $15 \mathrm{~km}$ and found that adjusting tangent altitudes to align pressure levels resulted in changes on the order of $0.1 \mathrm{~km}$, so retrievals were left on the ACE-FTS altitude grid.

\section{Results}

\subsection{Retrieval sensitivity}

The motivation behind the method for retrieving $P / T$ vertical profiles presented here was to reduce the reliance on highquality a priori quantities and model input that the ACE-FTS retrievals use. Spectral fitting requires a priori vertical profiles of temperature, pressure, and trace gas VMRs to compute a first-guess spectrum. When used for spectra recorded from the surface, such as for TCCON, GFIT scales the VMR vertical profiles, so errors in their shape lead to errors in the 


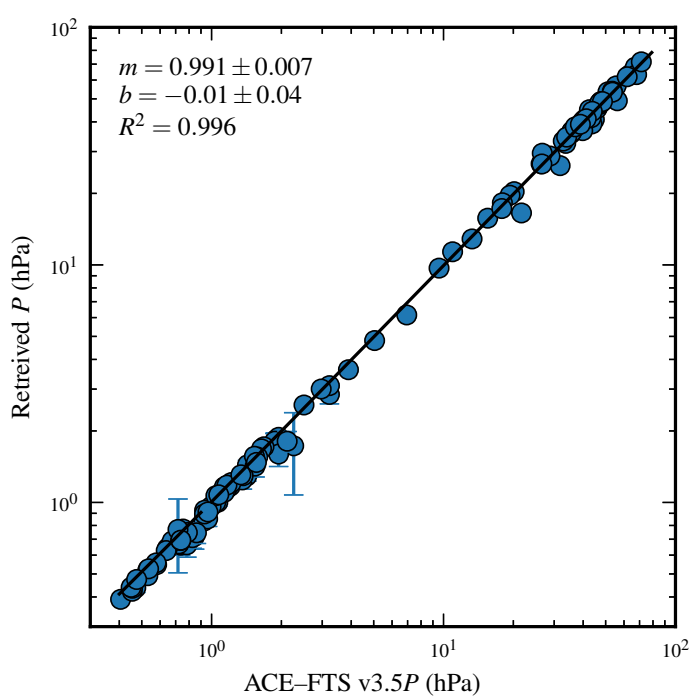

Figure 3. Correlation between retrieved pressure at the $P_{a}$ level between this work ( $y$ axis) and ACE-FTS v3.5 ( $x$ axis) for 124 ACEFTS occultations. The range of $P$ values corresponds to the range of altitudes chosen by the retrieval algorithm to be the $P_{a}$ level. Error bars are uncertainty in retrieved $P_{a}$.

retrieved profile (Wunch et al., 2011). For solar occultation applications, the shape of the VMR vertical profile below the highest observation altitude will be allowed to change since measurements are made at all altitudes and trace gas retrievals should not be sensitive to the a priori VMRs (Boone et al., 2005). A priori closer to the true state of the atmosphere can reduce errors in retrieved gas VMR, however, by increasing the speed of convergence, especially when spectral lines from interfering species overlap. The quality of fit, and therefore the trace gas retrieval, is more sensitive to the spectral micro-windows used than to the VMR a priori.

The methods presented here for $P / T$ retrievals specifically rely on the a priori vertical profiles of $\mathrm{CO}_{2} \mathrm{VMR}, T$, and $P$. Retrievals are done by fitting $\mathrm{CO}_{2}$ lines using an existing profile. As with other trace gas retrievals, fitting results should not be sensitive to the $\mathrm{CO}_{2}$ a priori, if the fits are good, and assumes the VSF for $\mathrm{CO}_{2}$ is not unity. $\mathrm{CO}_{2}$ in the Martian atmosphere is well mixed and its vertical profile is nearly constant up to $80-100 \mathrm{~km}$, similar to on Earth (e.g. Forget et al., 1999). Its VMR is around $95 \%$, making it ideally suited for use in $P / T$ retrievals, since it will have strong absorption features and minimal interference from other gases. It has also been closely monitored by multiple spacecraft for over a decade. ExoMars TGO was to include an updated version of the Mars Climate Sounder on the Mars Reconnaissance Orbiter to continue these measurements (it would have used a different viewing geometry and so could not make co-located measurements of the same air mass and so cannot be used to directly provide a priori). A priori profiles for the MATMOS mission were to have been provided by the CMC's Global Environmental Multiscale Model (GEM), which would be continuously constrained by new observations.

Accurate $T$ and $P$ a priori profiles have a higher impact on retrieval quality than $\mathrm{CO}_{2}$ VMR since $T$ is directly computed from the a priori $T$ in Eq. (5). The sensitivity of the retrievals to the a priori temperature was tested using Earthobserving spectra by perturbing the a priori temperature profile by $\pm 5, \pm 10$, and $\pm 20 \mathrm{~K}$ (with random noise added within $3 \mathrm{~K}$ of the perturbation). Systematic errors in the a priori $T$ of around $\pm 5 \mathrm{~K}$ had little effect on the retrieval $T$, except at altitudes greater than $80 \mathrm{~km}$, where oscillations were increased or amplified. Systematic errors in the a priori $T$ greater than $10 \mathrm{~K}$ reduced the stability of the retrieval and led to unphysical oscillations at all altitudes. Fewer $\mathrm{CO}_{2}$ vibration-rotation bands passed quality criteria at each altitude as well. Aside from the dependence on a priori temperature in Eq. (5), the spectral fits also depend on temperature. Spectra computed at the wrong temperature have incorrect line strengths and cause a fit to result in an incorrect VSF. On Earth, a priori errors on the order of $10 \mathrm{~K}$ are expected to occur only at very high altitudes, above $70 \mathrm{~km}$. At such altitudes, the retrieval algorithm presented is impacted by weaker absorption by $\mathrm{CO}_{2}$ as density decreases, loss of accuracy in the a priori $\mathrm{CO}_{2}$ VMR as it falls off, and the departure from local thermodynamic equilibrium.

Application of this method to a mission to Mars will strive to provide the highest-quality a priori temperature possible from observations and models, and this method is intended to improve those a priori for use in trace gas retrievals. The method's dependence on pressure is less severe since pressure is constrained by the equation of hydrostatic equilibrium. Pressure does not vary strongly diurnally, unlike temperature, and though it varies seasonally, this retrieval scheme is independent of surface pressure.

The initial objective of a MATMOS-like mission would be trace gas detection, which would be initially achieved using spectral absorption features and fitting, followed by an estimation of their abundances and then vertical profiles. During the duration of the mission, the retrievals would continue to be developed and improved, including updating the a priori and spectral windows. Examining the vertical distribution of target gases will be the most challenging aspect of a MATMOS-like mission, especially at higher altitudes where $P / T$ retrievals become more difficult. The low pressure and density of the Martian atmosphere and low expected VMRs of target gases will result in very weak absorption features, while the assumptions of hydrostatic equilibrium and local thermal equilibrium also become less valid at higher altitudes. The vertical range through which each of the 10 $\mathrm{CO}_{2}$ bands used is effective is chosen automatically by the $P / T$ retrieval algorithm based on fitting uncertainties. Once a MATMOS-like mission is underway, a qualitative examination of the effective altitude range of each band could be 
performed, and fitting could be restricted to those altitudes to improve retrieval stability and speed.

\subsection{ACE-FTS data sets}

The ACE-FTS v2.2 temperature product was thoroughly validated by Sica et al. (2008), which included a preliminary discussion about ACE-FTS v3.0 temperature. Comparisons were made against data from three lidar locations, 31 radiosonde locations, the SPectromètre Infra Rouge pour l'étude de l'Atmosphère par diodes Laser Embarquées (SPIRALE) balloon-borne spectrometer, and three satellite instruments: the Sounding of the Atmosphere using Broadband Emission Radiometry (SABER), the Michelson Interferometer for Passive Atmospheric Sounding (MIPAS), and the Halogen Occultation Experiment (HALOE). ACE-FTS v2.2 temperatures agreed with other sensors within $2 \mathrm{~K}$ in the stratosphere and upper troposphere and within $5 \mathrm{~K}$ in the mesosphere, but they exhibited a warm bias of 3-6 K in the mesosphere. A previous comparison with the Microwave Limb Sounder (MLS) found a larger bias of 5-7 K in the mesosphere (Schwartz et al., 2008). An agreement between ACE-FTS v2.2, SABER, and MLS within $5 \mathrm{~K}$ in the tropopause and lower stratopause was confirmed while studying the Arctic winters by Manney et al. (2008), while differences of $\pm 2 \mathrm{~K}$ were found between ACE-FTS v1.0 and sondes and lidar during the Arctic ACE validation campaign in 2004 (Kerzenmacher et al., 2005). In support of that campaign, Nowlan et al. (2013) performed a temperature and pressure retrieval using measurements of the $\mathrm{O}_{2} \mathrm{~A}$ and $\mathrm{B}$ bands made by the Measurement of Aerosol Extinction in the Stratosphere and Troposphere Retrieved by Occultation (MAESTRO) instrument on SCISAT and compared their results to ACE-FTS v2.2 and sondes. The sondes matched ACE-FTS within 2-4 K, and MAESTRO and ACE-FTS had a mean difference of $5 \mathrm{~K}$. Mamun et al. (2013) compared GEM simulated temperature and water vapour to ACE-FTS v2.2 and MLS and found an agreement of $<2 \mathrm{~K}$ in the troposphere and $<5 \mathrm{~K}$ in the stratosphere, but they noted that GEM tended to agree more closely with MLS than ACE-FTS about the height of the tropopause and stratopause.

Validation of High Resolution Dynamics Limb Sounder (HIRDLS) temperature retrievals included a comparison with sondes, COSMIC, and ACE-FTS v2.2 (Gille et al., 2008). HIRDLS was found to be warmer than the sondes by $1-2 \mathrm{~K}$ and warmer than COSMIC by about $1 \mathrm{~K}$ between 15 and $40 \mathrm{~km}$. HIRDLS tended to be warmer than ACEFTS in the lower portion of that altitude range, and cooler higher, with differences of $\pm 3 \mathrm{~K}$. MIPAS temperature validation used ACE-FTS v3.0 but only four coincident measurements (Stiller et al., 2012). Temperature differences vary up to $\pm 3 \mathrm{~K}$, with maxima in the middle stratosphere, and there continued to be a bias at $23 \mathrm{~km}$. A separate study examining MIPAS kinetic temperatures above $45 \mathrm{~km}$ observed ACE-FTS v2.2 to be consistently warmer than MIPAS above
$50 \mathrm{~km}$, with increasing magnitude to $\sim 10 \mathrm{~K}$ near $80 \mathrm{~km}$ (García-Comas et al., 2012). An updated version of MIPAS temperature data was compared to ACE-FTS v3.0 by GarcíaComas et al. (2014), as well as SABER, MLS, the Optical Spectrograph and InfraRed Imaging System (OSIRIS), and the Solar Occultation For Ice Experiment (SOFIE). The new version generally exhibits $1-2 \mathrm{~K}$ better agreement with the other instruments below $80 \mathrm{~km}$. MIPAS and ACE-FTS agree within $2 \mathrm{~K}$ below $80 \mathrm{~km}$, except in summer, when differences are between -15 and $3 \mathrm{~K}$. They note that in the summer, between 40 and $60 \mathrm{~km}$, MIPAS is $3 \mathrm{~K}$ warmer than ACEFTS v3.0 than when compared to ACE-FTS v2.2 in GarcíaComas et al. (2012), likely due to the changes between the two ACE-FTS versions.

OSIRIS retrieved temperature profiles were compared to SABER, SOFIE, ACE-FTS v2.2, and ACE-FTS v3.0 (Sheese et al., 2012). Comparison with ACE-FTS found that ACEFTS was $9 \mathrm{~K}$ warmer at $48 \mathrm{~km}$ but less than $3 \mathrm{~K}$ warmer between 60 and $80 \mathrm{~km}$. A difference of only $0-2 \mathrm{~K}$ is observed between ACE-FTS v2.2 and v3.0 in the region where a bias of 3-6 K was reported by previous studies. Validation of SOFIE was done using SABER, MLS, ACE-FTS v2.2 (Marshall et al., 2011), and ACE-FTS v3.0 (Stevens et al., 2012). SOFIE and ACE-FTS v2.2 agree within $2 \mathrm{~K}$ through the troposphere and stratosphere, SOFIE being warmer at the stratopause $(3-5 \mathrm{~K})$ and cooler through the mesosphere (4 K in summer). ACE-FTS v3.0 comparisons were done for the Arctic in July, exhibiting the same trend as against ACE-FTS v2.2, and for the Antarctic between December and January, which is similar, with differences of only $\sim 1 \mathrm{~K}$. In general, ACE-FTS agrees with other instruments within $2-5 \mathrm{~K}$, with v2.2 exhibiting a warm bias in the mesosphere of $3-6 \mathrm{~K}$ and a reduction in $\mathrm{v} 3.0$ to only $2 \mathrm{~K}$.

Six sets of ACE-FTS data were analysed to provide different seasonal and zonal coverage. Details about the sets are provided in Table 2 and a complete list of ACE-FTS occultations used can be found in the Supplement. Five of the sets feature occultations selected in coincidence with COSMIC observations. The sixth set is of 24 occultations measured between 2005 and 2008 over the Middle East. The Middle East occultations generally have low $\beta$ angles and have a mean altitude spacing of $3.8 \mathrm{~km}$. They are all between 49 and $87^{\circ} \mathrm{E}$ longitude and 28 and $35^{\circ} \mathrm{N}$ latitude. The Arctic 2010 set consists of 30 occultations restricted to latitudes above $62^{\circ} \mathrm{N}$ measured in 2010, and 13 occultations are coincident with COSMIC measurements within $3 \mathrm{~h}$ and $400 \mathrm{~km}$.

The remaining four sets are composed of ACE-FTS occultations for which there are COSMIC coincidences within less than $150 \mathrm{~km}$ and $1 \mathrm{~h}$. Three of these sets also satisfy a seasonal and zonal restriction, while the fourth is composed of measurements over the tropics with no restriction on time of year. Occultations in this set, denoted low latitudes, were chosen for their very high $\beta$ angles and small vertical spacing (mean of $3.2 \mathrm{~km}$ ) in order to examine whether tight altitude spacing strongly affected the quality of retrievals. 
Table 2. List of ACE-FTS occultation sets analysed by GGG, showing the number of occultations each contains, their zonal coverage, season, and altitude spacing.

\begin{tabular}{|c|c|c|c|c|c|c|}
\hline Set name & $\begin{array}{l}\text { Set } \\
\text { size }\end{array}$ & $\begin{array}{l}\text { Longitude } \\
\text { range }\end{array}$ & $\begin{array}{l}\text { Latitude } \\
\text { range }\end{array}$ & $\begin{array}{l}\text { Mean } z \\
\text { spacing }\end{array}$ & $\begin{array}{l}\sigma \text { of } z \\
\text { spacing }\end{array}$ & Time frame \\
\hline Arctic 2010 & 30 & unrestricted & $62-78^{\circ} \mathrm{N}$ & $5.6 \mathrm{~km}$ & $1.2 \mathrm{~km}$ & Mar-Nov 2010 \\
\hline Middle East & 24 & $49-87^{\circ} \mathrm{E}$ & $28-35^{\circ} \mathrm{N}$ & $3.8 \mathrm{~km}$ & $0.9 \mathrm{~km}$ & Jul 2004-Aug 2010 \\
\hline Arctic fall & 16 & unrestricted & $62-84^{\circ} \mathrm{N}$ & $4.9 \mathrm{~km}$ & $1.1 \mathrm{~km}$ & Sept-Nov 2009; Sept-Nov 2010 \\
\hline Arctic winter & 23 & unrestricted & $56-79^{\circ} \mathrm{N}$ & $4.4 \mathrm{~km}$ & $2.2 \mathrm{~km}$ & $\begin{array}{l}\text { Jan-Feb 2009; Jan-Feb 2010; } \\
\text { Jan-Feb 2011; Jan-Feb } 2012\end{array}$ \\
\hline Antarctic spring & 29 & unrestricted & $58-84^{\circ} \mathrm{S}$ & $4.3 \mathrm{~km}$ & $1.3 \mathrm{~km}$ & $\begin{array}{l}\text { Mar-May 2009; Mar-May 2010; } \\
\text { Mar-May } 2011\end{array}$ \\
\hline Low latitudes & 7 & unrestricted & $34^{\circ} \mathrm{S}-27^{\circ} \mathrm{N}$ & $3.2 \mathrm{~km}$ & $1.1 \mathrm{~km}$ & Apr 2009-Feb 2012 \\
\hline
\end{tabular}

The Arctic fall and Antarctic spring sets were originally chosen to also examine the effect of altitude spacing. Arctic fall occultations were measured during the months September, October, or November in 2009 and 2010 and are above $62^{\circ} \mathrm{N}$. Antarctic spring occultations were measured during the months March, April, or May, between the years 2009 and 2012 , and are below $58^{\circ} \mathrm{S}$. Arctic fall originally consisted of 14 occultations with a mean $z$ spacing of $3.2 \mathrm{~km}$ and standard deviation of $1 \mathrm{~km}$, and Antarctic spring originally consisted of 10 occultations with a mean $z$ spacing of $5.5 \mathrm{~km}$ and standard deviation of $0.2 \mathrm{~km}$. Smaller $z$ spacing provides more information for interpolation to a $1 \mathrm{~km}$ grid, which is where comparisons to ACE-FTS are made, while large $z$ spacing means the observation is made over a wide altitude range with varying temperature and pressure from start of acquisition to end. With these sets, however, no improvement to retrieval quality (large deviations from a priori or ACE-FTS retrievals) was found with tight $z$ spacing. Quality issues were mostly the result of errors in tangent altitude and interpolation, which were later resolved. To improve the statistics of mean difference temperature profiles, we increased the size of these sets without a restriction in $z$ spacing and also added the Arctic winter set. Arctic winter occultations are above $56^{\circ} \mathrm{N}$, measured in the months of January or February between 2009 and 2012.

\subsection{Retrieved $T$ profiles and ACE-FTS comparison}

Vertical profiles of $T$ are interpolated onto an altitude grid with $1 \mathrm{~km}$ spacing for comparison, using a three-point, piecewise quadratic scheme. Over each set, we compute the mean and standard deviation at each altitude on the $1 \mathrm{~km}$ grid, at altitudes where ACE-FTS $T$ retrievals were successful. The means and standard deviations of each set, for both ACE-FTS and GGG retrievals, are shown in Fig. 4.

There are two sets comprised of warm, low-latitude occultations (Fig. 4b and f): Middle East and low latitudes. These are characterized by a sharp and low-altitude tropopause, a lower stratopause, and small variability between occultations, as demonstrated by the small standard deviations in both ACE-FTS and GGG retrievals. The low-latitude set exhibits the most structure at higher altitudes, $75-100 \mathrm{~km}$, with the retrievals presented here having larger mean $T$ variations with altitude than ACE-FTS but similar variability.

The Arctic 2010 set, Fig. 4a, is not restricted to a single season and thus has the largest variability. The Arctic winter, Fig. 4d, set is seasonally restricted, but it also features large variability, especially at low altitudes. These profiles were all recorded in January or February, without any longitudinal restriction. They are mostly around $65^{\circ} \mathrm{N}$ and all are over land. Four occultations are in the high Arctic, at latitudes between 73 and $79^{\circ} \mathrm{N}$, and have tropopause temperatures of $200 \mathrm{~K}$, whereas five occultations were recorded below $60^{\circ} \mathrm{N}$ and have tropopause temperatures of $220 \mathrm{~K}$. Note the similar standard deviations from both ACE-FTS and GGG retrievals for the Arctic winter set. A common feature of these profiles, occurring in $70 \%$ of them, is temperature oscillations above the tropopause, which is seen in our a priori, our retrievals, and the ACE-FTS retrievals. In the Arctic winter set, our a priori $T$ profiles have larger deviations from the ACEFTS retrievals than in any other set, over $30 \mathrm{~K}$ near $50 \mathrm{~km}$ in some cases, which strongly affects our ability to reproduce the ACE-FTS retrievals due to the dependence in Eq. (5). This is clearly visible in Figs. $4 d$ and $5 d$. Our retrievals tend to have more $T$ oscillations than ACE-FTS, and this can be seen in the mean profiles.

The Arctic fall set, Fig. 4c, has moderate variability, and the mean $T$ profiles exhibit the best agreement between ACE-FTS and this work. The structure between 70 and $100 \mathrm{~km}$ is reproduced by both retrievals, while below $35 \mathrm{~km}$, the ACE-FTS mean is smoother.

The Antarctic spring set, Fig. 4e, has polar measurements with large $\beta$ angles, as well as tight altitude spacing, which should improve retrievals due to the increased density of measurements. Deviations from the a priori or ACE-FTS retrievals tend to be less frequent and smaller, and those introduced by interpolation to the $1 \mathrm{~km}$ grid are eliminated. Smallscale structure is also better captured, which is especially important if there is uncertainty in tangent altitudes. Our 


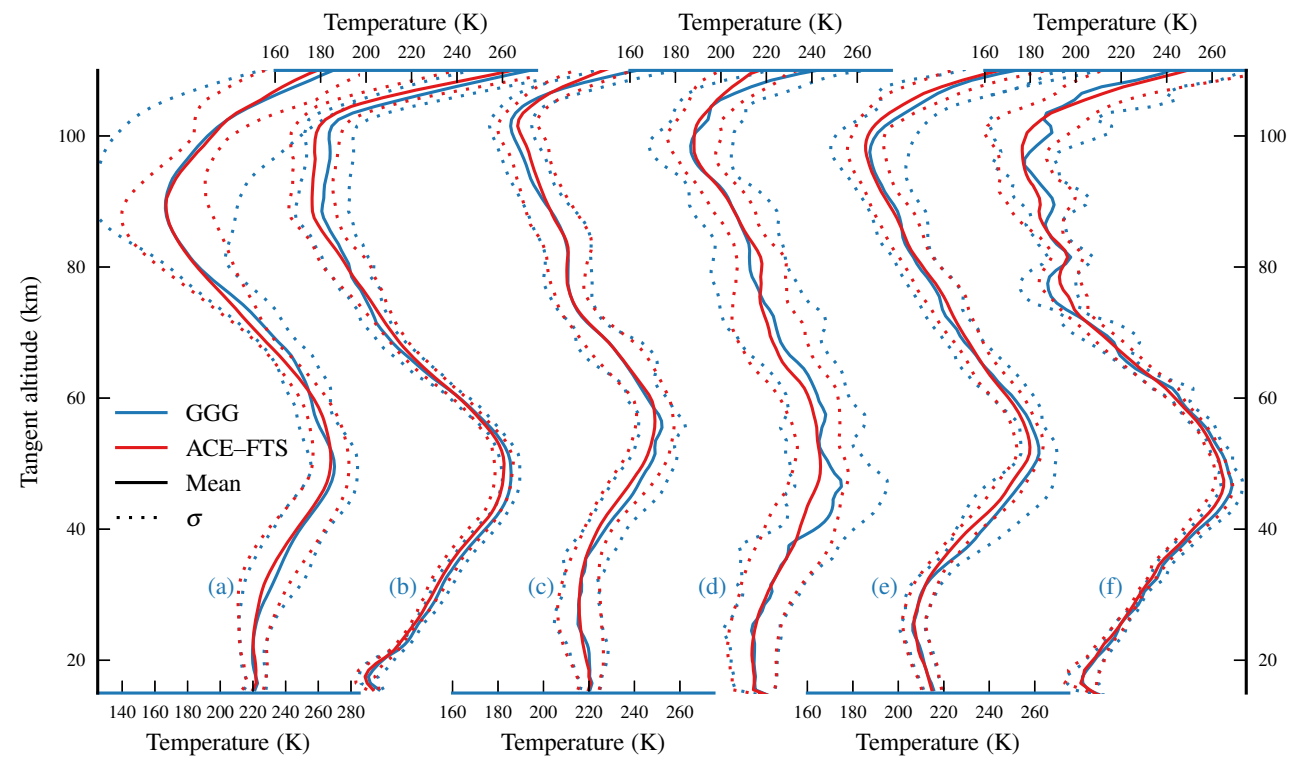

Figure 4. Mean $T$ profiles for each set of occultations in Table 2: (a) Arctic 2010, (b) Middle East, (c) Arctic fall, (d) Arctic winter, (e) Antarctic spring, and (f) low latitudes. Solid lines are mean $T$ profiles for each set, and dashed lines are \pm their respective standard deviations. The blue lines represent retrieved $T$ profiles from GGG and the red lines represent ACE-FTS v3.5 retrievals. Means are computed on the $1 \mathrm{~km}$ interpolated grid; see Table 2 for the number of occultations in each set.
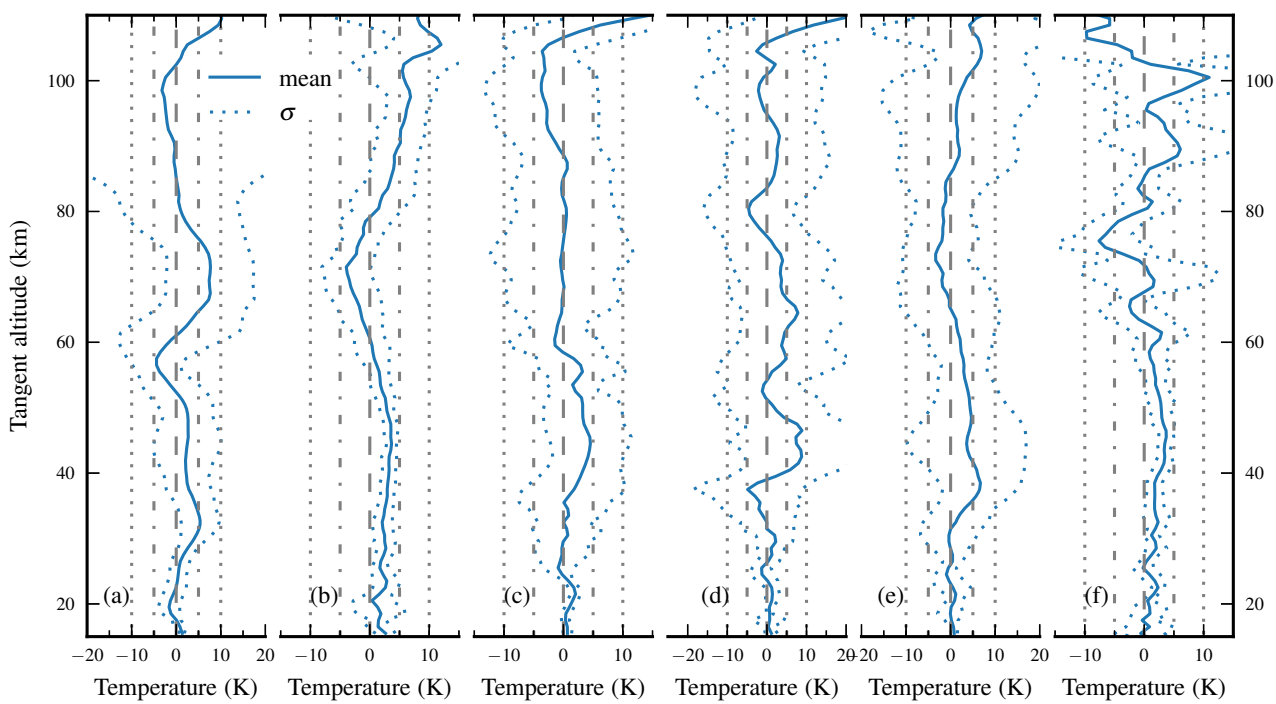

Figure 5. The mean of the differences between temperature profiles retrieved by GGG and ACE-FTS v3.5 (GGG - ACE) for each set of occultations in Table 2: (a) Arctic 2010, (b) Middle East, (c) Arctic fall, (d) Arctic winter, (e) Antarctic spring, and (f) low latitudes. Standard deviations are shown as dashed lines $( \pm)$.

retrieved profiles exhibit more variability than those from ACE-FTS, and they tend to be colder in the mesosphere.

Figure 5 shows the mean of the differences between this work and ACE-FTS retrievals for each set, which are generally within $\pm 3 \mathrm{~K}$ except at peaks in the mid-stratosphere and mid-mesosphere. Figure $5 \mathrm{~b}$ and $\mathrm{c}$ have the smallest mean differences (GGG $-\mathrm{ACE}$ ), less than $\pm 5 \mathrm{~K}$, followed by Fig. $5 \mathrm{e}$, which exceeds $-5 \mathrm{~K}$ near $35 \mathrm{~km}$, and Fig. 5f, which exceeds
$5 \mathrm{~K}$ near $75 \mathrm{~km}$. Figure $5 \mathrm{a}$ and $\mathrm{d}$ have the largest differences of around $\pm 7.5 \mathrm{~K}$ at several altitudes. A similar structure appears in all six panels: the GGG profiles match ACEFTS very closely in the troposphere, are consistently warmer in the mid-stratosphere, have zero crossings near $60 \mathrm{~km}$ in Fig. 5a-f (which corresponds to the stratopause in Fig. 4af), and are cooler in the mesosphere. The mid-stratospheric differences are around $-4 \mathrm{~K}$ (except for Arctic winter) and 


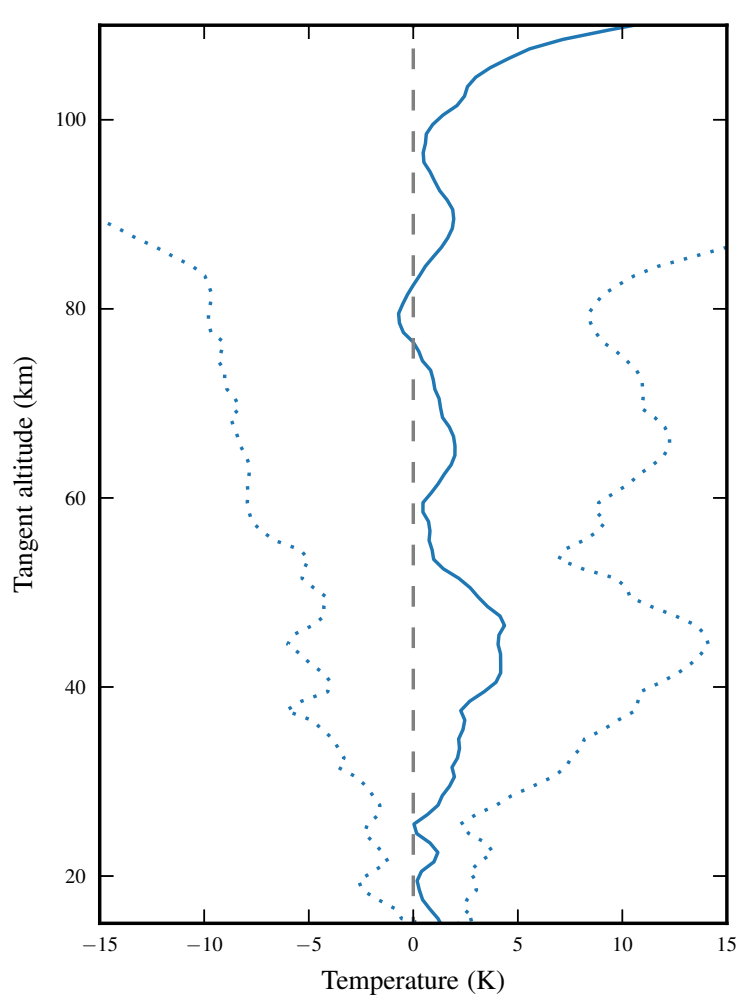

Figure 6. Mean and standard deviation of the differences in retrieved temperature between GGG and ACE-FTS v3.5 retrievals (GGG - ACE) for all 129 occultations in Fig. 5. The largest difference occurs near $40 \mathrm{~km}$ and is mostly attributed to the Arctic winter set, Fig. 5d.

indicate a bias in our retrievals, since no bias in ACE-FTS retrievals at these altitudes has been indicated by other comparisons. In the mesosphere, we find GGG can be $3-5 \mathrm{~K}$ cooler than ACE-FTS but not uniformly so. In this altitude range, there is a known warm bias observed in ACE-FTS v2.2 by Sica et al. (2008) and seen persisting in ACE-FTS v3.0 by Sheese et al. (2012) and Stevens et al. (2012), but it reduced to only $\sim 2 \mathrm{~K}$.

Figure 6 shows the mean of the differences for all 129 occultations and has a shape as described above. Below $100 \mathrm{~km}$, the mean (GGG - ACE) is between $+5 \mathrm{~K}$ (in the midstratosphere) and $-0.7 \mathrm{~K}$ (in the mesosphere) with standard deviations on the order of $\sim 10 \mathrm{~K}$. The mean tends towards 0 near $50 \mathrm{~km}$, corresponding to the stratopause in Fig. 4, but remains above 0 , except at $80 \mathrm{~km}$. Thus we confirm a warm bias in the GGG retrievals, stronger in the stratosphere. This bias was initially attributed to errors in altitude determination, as it appeared that the profiles were very similar, but that GGG temperatures were at lower altitudes than those of ACE-FTS. As detailed in Sect. 2.2, we attempted to mediate altitude errors, but this did not fully resolve the bias. If our altitudes are correct, then the bias could be due to errors in our a priori $T, P$, or gas VMRs, which are chosen for each spectrum from the tangent altitude. The same a priori VMRs were used for all occultations, but $\mathrm{CO}_{2}$ is constant below $80 \mathrm{~km}$ and only a few well-known molecules interfere in the windows used. The a priori $T$ and $P$ are unique for each occultation and would more likely produce random errors. When compared to the a priori used by GGG, ACE-FTS is predominantly $0.5 \mathrm{~K}$ cooler, except near $90 \mathrm{~km}$, where ACEFTS is $1 \mathrm{~K}$ warmer. It should be noted that $50 \mathrm{~km}$ is the altitude of the crossover pressure in the ACE-FTS retrievals, where a different retrieval scheme is used above and below. However, if the bias were in the ACE-FTS data, this would have been identified when performing $P-T$ validation as in Sica et al. (2008).

\subsection{COSMIC comparison}

GPS signals passing through the atmosphere experience refraction, which causes a phase delay before being received by a COSMIC satellite. Vertical profiles of bending angle are obtained from the phase data and are used to compute refractivity, which depends on $T, P$, water vapour, and electron density. The primary data products are high-resolution ( $\sim 1 \mathrm{~km}$ ) vertical profiles of $T$ and $\mathrm{H}_{2} \mathrm{O}$ vapour pressure up to $40 \mathrm{~km}$. The precision of the technique was verified after launch when the six satellites were in close proximity by comparison with each other (Schreiner et al., 2007). COSMIC has been extensively compared to other data sets and is in close agreement with only small biases.

COSMIC results have been compared to other GPS radio occultation satellites, the CHAllenging Minisatellite Payload for geoscientific research (CHAMP) and the Gravity Recovery and Climate Experiment (GRACE-A), and found to have consistent climatologies within $0.05 \%$ (Foelsche et al., 2011). Over Antarctica, Wang et al. (2013) found COSMIC to be consistent with sondes but also to have a warm bias of $1 \mathrm{~K}$ when compared to satellite measurements made by the Advanced InfraRed Sounder (AIRS), the Infrared Atmospheric Sounding Interferometer (IASI), the Advanced TIROS Operational Vertical Sounder (ATOVS), and the Microwave Integrated Retrieval System (MIRS). Previous comparisons with sondes over Antarctica showed a 1-2 K cold bias (Wang and Lin, 2007), which was also seen in CHAMP. A comparison between CHAMP and COSMIC over Australia found only a $0.4 \mathrm{~K}$ mean temperature difference (Zhang et al., 2011). Another sonde campaign with near global coverage and many different types of sondes also found that COSMIC had a cold bias (Sun et al., 2010), but it was less than $1 \mathrm{~K}$ and consistent with Wang et al. (2013). COSMIC $T$ validation has recently been reported by Das and Pan (2014) against SABER and MLS. COSMIC was found to be 3-4 K colder than SABER at low altitudes (10-20 km), but increasing steadily to more than $5 \mathrm{~K}$ warmer above $40 \mathrm{~km}$. MLS and COSMIC agreed within $3 \mathrm{~K}$, and no bias towards season or latitude was shown for either MLS or SABER. Gille et al. (2008) compared COSMIC to HIRDLS and ACE-FTS 

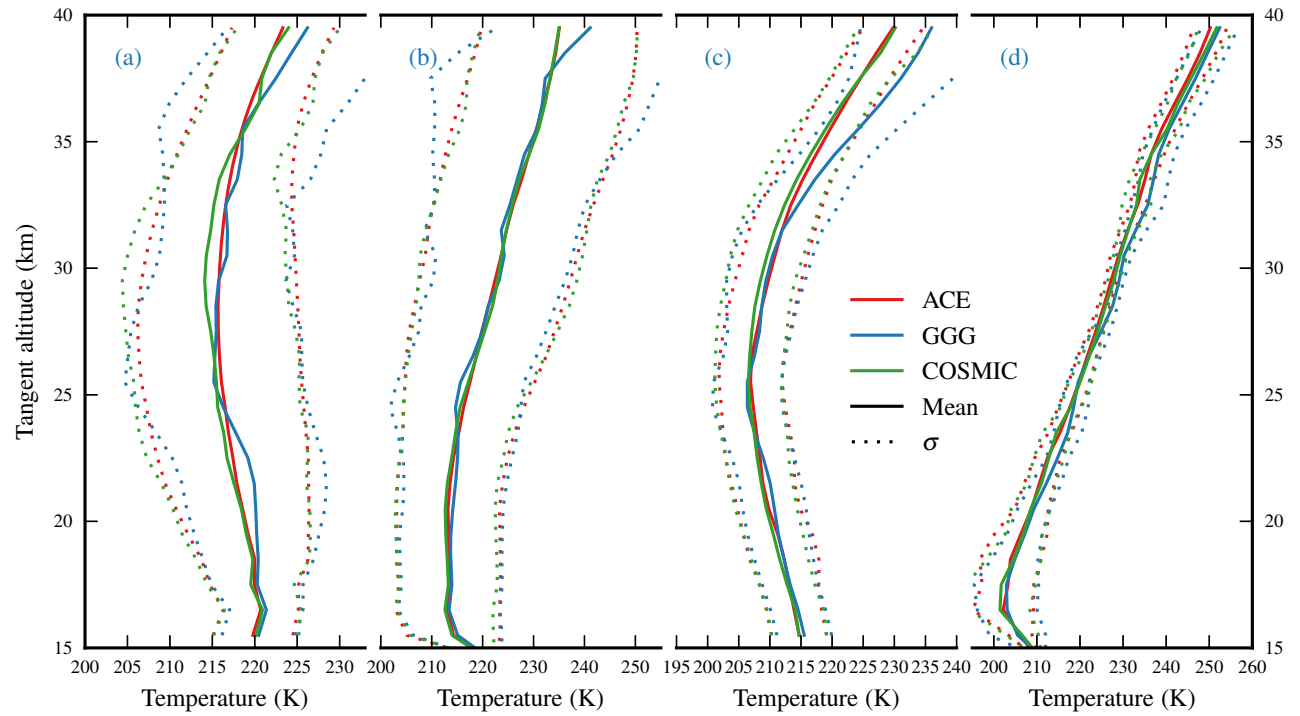

Figure 7. Mean temperature profiles retrieved by ACE-FTS v3.5 (red), GGG (blue), and COSMIC (green) for sets: (a) Arctic fall, (b) Arctic winter, (c) Antarctic spring, and (d) low latitudes. Means are solid lines, and standard deviations are dashed. The maximum altitude of the COSMIC data set is $40 \mathrm{~km}$.

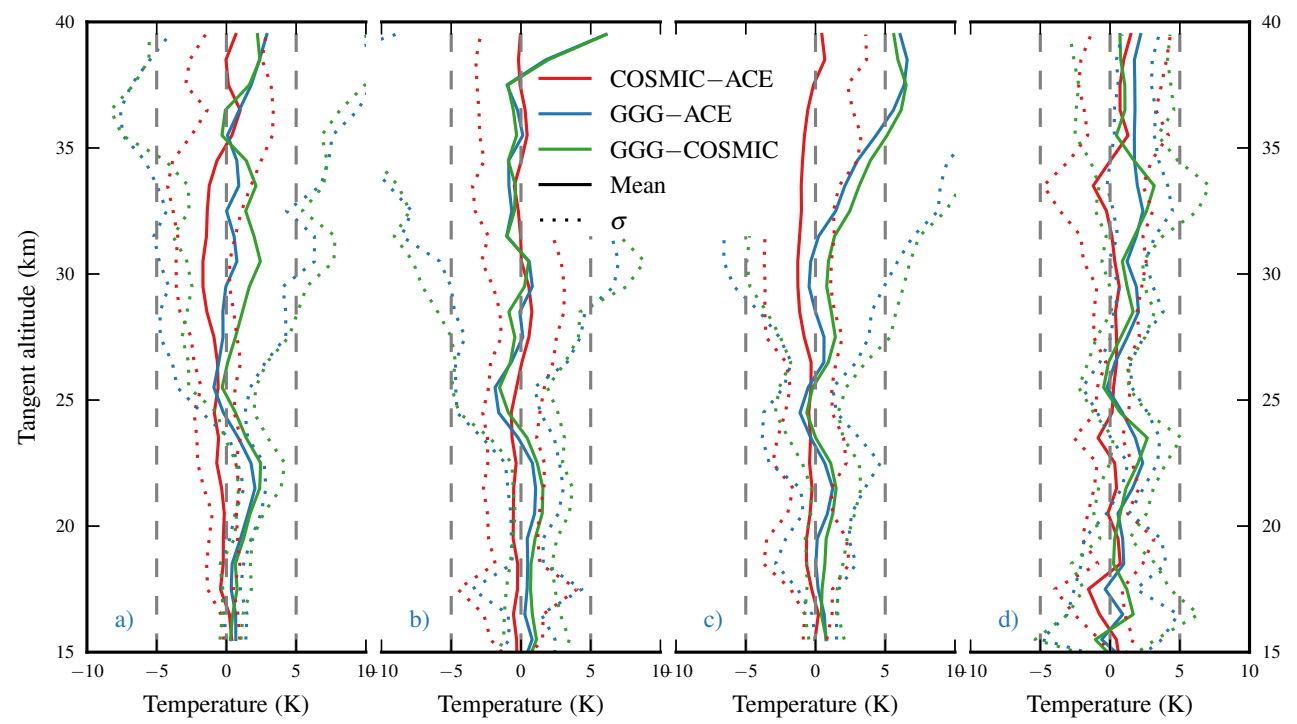

Figure 8. The mean of the differences between temperature profiles retrieved by GGG, ACE-FTS v3.5, and COSMIC for sets: (a) Arctic fall, (b) Arctic winter, (c) Antarctic spring, and (d) low latitudes. Shown are COSMIC - ACE (red), GGG - ACE (blue), and GGG - COSMIC (green). Means are solid lines, and standard deviations are dashed.

v2.2 and also found COSMIC to be about $1 \mathrm{~K}$ colder (see Sect. 3.2). COSMIC has also been compared to several data assimilation products which revealed a $2 \mathrm{~K}$ temperature bias, but warm in the Northern Hemisphere and cold in the Southern Hemisphere (Kishore et al., 2009). COSMIC has been to shown to agree closely with sondes and satellite instruments within less than $1-3 \mathrm{~K}$, but the differences are consistently with COSMIC colder.

Vertical profiles of mean temperature for all COSMIC radio occultations coincident with ACE solar occultations are shown in Fig. 7, divided seasonally and zonally as in Table 2, alongside ACE-FTS v3.5 and profiles retrieved from ACEFTS by GGG. Comparing GGG to ACE-FTS v3.5 we see that GGG is warmer than ACE-FTS except around $25 \mathrm{~km}$, the altitude of a known feature in the ACE-FTS v2.2 data product caused by the empirical function used to determine pressure in this region. It is discussed in Sica et al. (2008) and seen in other comparisons (e.g. Gille et al., 2008) with v2.2 data. This effect has been reduced in the v3.5 data product (Boone et al., 2013) but was still noted by Stiller et al. (2012). 


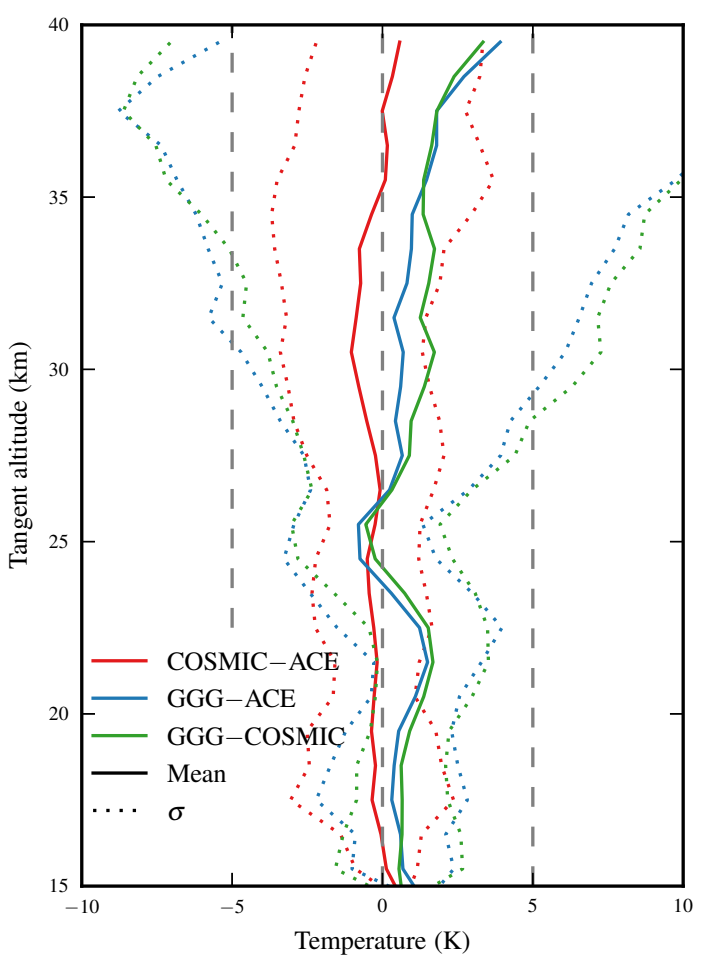

Figure 9. Mean and standard deviations of the differences in retrieved temperature between temperature profiles retrieved by GGG, ACE-FTS v3.5, and COSMIC for all 74 occultations in Fig. 8. Shown are COSMIC - ACE (red), GGG - ACE (blue), and GGG - COSMIC (green). Means are solid lines, and standard deviations are dashed.

In Fig. 7 there is no discernible feature in the ACE-FTS v3.5 profiles, while the GGG profiles are seen to oscillate about the ACE-FTS and COSMIC profiles in all four panels.

In the lower stratosphere and upper troposphere, the shapes of mean $T$ profiles in our four zonally and seasonally restricted data sets are very different, featuring different tropopause heights and lapse rates. The mean differences between our retrievals with GGG and the COSMIC and ACEFTS v3.5 data products share a consistent shape, shown in Fig. 8. There are no significant dependencies on latitude or season in these $T$ differences. We see that GGG is warmer than COSMIC by $<2 \mathrm{~K}$ below $24 \mathrm{~km}$, where COSMIC is known to be cold, GGG is consistently cooler than COSMIC between 24 and $30 \mathrm{~km}$ by $1-4 \mathrm{~K}$, and GGG is again warmer than COSMIC by $3-5 \mathrm{~K}$ between 30 and $40 \mathrm{~km}$. The closest agreement with COSMIC is seen in the low-latitude set, Fig. $8 \mathrm{~b}$, where the differences are between -1.7 and $0.9 \mathrm{~K}$, while the largest differences are seen in the Antarctic spring set, Fig. 8c, with maxima of -6.5 and $3.5 \mathrm{~K}$.

Considering all 72 occultations in these four data sets without restriction, shown in Fig. 9, we find the ACE-FTS v3.5 and the COSMIC data products agree with each other within -0.9 and $0.5 \pm 0.3 \mathrm{~K}$, with COSMIC predominantly exhibiting a $<0.5 \mathrm{~K}$ cold bias. This agrees with previous results in which ACE-FTS and COSMIC both show close agreement with sondes within a few K; however, COSMIC generally has a small cold bias relative to other data products, as discussed above. The difference between the GGG retrievals and those from COSMIC reflects that GGG also deviates from COSMIC where GGG deviates from ACE-FTS v3.5. However, below $30 \mathrm{~km}$ we have the best agreement with ACE-FTS, where mean differences are within -2 and $3 \mathrm{~K}$.

\section{Conclusions}

An improved technique to retrieve vertical profiles of temperature and pressure from high-resolution infrared solar occultation spectra has been developed, with the intention that it finds application on a future Mars mission. We have demonstrated the technique's success and evaluated the quality of the retrievals by comparing with two satellite data products: COSMIC and ACE-FTS v3.5. Pressure is constrained by the equation of hydrostatic equilibrium and retrieved values are closely correlated to those from ACE-FTS v3.5.

We find that GGG temperature retrievals are predominantly warmer than ACE-FTS by $2 \mathrm{~K}$ in the tropopause, up to $5 \mathrm{~K}$ in the stratosphere, and between -3 and $1 \mathrm{~K}$ in the mesosphere. The largest deviations occur at the tropopause and stratopause, which can occur at different altitudes. No seasonal or zonal biases are found. We find very good agreement between ACE-FTS v3.5 and COSMIC, with mean differences of $<1 \mathrm{~K}$ below $40 \mathrm{~km}$. COSMIC exhibits a cold bias, consistent with other profile comparisons. When GGG is compared to COSMIC, mean differences are within -2 and $3 \mathrm{~K}$ below $35 \mathrm{~km}$. GGG is warmer than COSMIC at all altitudes except near $25 \mathrm{~km}$, near the tropopause.

The objective was to develop a technique with minimal reliance on high-quality a priori, model input, or empirical functions. With suitable refinement to the application of Martian solar occultation, this technique will be capable of retrieving accurate temperature and pressure profiles, enabling definitive detection of several trace gases in the atmosphere of Mars.

\section{The Supplement related to this article is available online at doi:10.5194/amt-9-1063-2016-supplement.}

Acknowledgements. Funding for this project was provided by the CSA and the Natural Sciences and Engineering Research Council of Canada (NSERC). We would like to thank the ACE Science Team for providing Level 1 data (spectra), for providing other input and output files from their own retrievals, and for their help and input throughput the project. We want to thank members of TCCON and collaborators on MATMOS for help with GGG and retrieval theory. The COSMIC Data Analysis and Archive Center provided their data for comparison through 
the website http://cdaac-www.cosmic.ucar.edu/cdaac/. NCEP reanalysis data were provided by the NOAA from their website http://www.cdc.noaa.gov/.

Edited by: F. Hase

\section{References}

Anthes, R. A., Bernhardt, P. A., Chen, Y., Cucurull, L., Dymond, K. F., Ector, D., Healy, S. B., Ho, S.-P., Hunt, D. C., Kuo, Y.-H., Liu, H., Manning, K., McCormick, C., Meehan, T. K., Randel, W. J., Rocken, C., Schreiner, W. S., Sokolovskiy, S. V., Syndergaard, S., Thompson, D. C., Trenberth, K. E., Wee, T.-K., Yen, N. L., and Zeng, Z.: The COSMIC/FORMOSAT-3 Mission: early results, B. Am. Meteorol. Soc., 89, 313, doi:10.1175/BAMS-89-3-313, 2008.

Aoki, S., Giuranna, M., Kasaba, Y., Nakagawa, H., Sindoni, G., Geminale, A., and Formisano, V.: Search for hydrogen peroxide in the Martian atmosphere by the Planetary Fourier Spectrometer onboard Mars Express, Icarus, 245, 177-183, doi:10.1016/j.icarus.2014.09.034, 2015.

Atreya, S. K., Mahaffy, P. R., and Wong, A.-S.: Methane and related trace species on Mars: origin, loss, implications for life, and habitability, Planet. Space Sci., 55, 358-369, doi:10.1016/j.pss.2006.02.005, 2007.

Barth, C. A., Stewart, A. I. F., Bougher, S. W., Hunten, D. M., Bauer, S. J., and Nagy, A. F.: Aeronomy of the current Martian atmosphere, in: Mars, edited by: Kieffer, H. H., Jakosky, B. M., Snyder, C., University of Arizona Press, Mildred Shapley Matthews, 1054-1089, 1992.

Bernath, P. F., McElroy, C. T., Abrams, M. C., Boone, C. D., Butler, M., Camy-Peyret, C., Carleer, M., Clerbaux, C., Coheur, P.F., Colin, R., DeCola, P., DeMazière, M., Drummond, J. R., Dufour, D., Evans, W. F. J., Fast, H., Fussen, D., Gilbert, K., Jennings, D. E., Llewellyn, E. J., Lowe, R. P., Mahieu, E., McConnell, J. C., McHugh, M., McLeod, S. D., Michaud, R., Midwinter, C., Nassar, R., Nichitiu, F., Nowlan, C., Rinsland, C. P., Rochon, Y. J., Rowlands, N., Semeniuk, K., Simon, P., Skelton, R., Sloan, J. J., Soucy, M.-A., Strong, K., Tremblay, P., Turnbull, D., Walker, K. A., Walkty, I., Wardle, D. A., Wehrle, V., Zander, R., and Zou, J.: Atmospheric Chemistry Experiment (ACE): mission overview, Geophys. Res. Lett., 32, L15S01, doi:10.1029/2005GL022386, 2005.

Bertaux, J.-L., Leblanc, F., Perrier, S., Quemerais, E., Korablev, O., Dimarellis, E., Reberac, A., Forget, F., Simon, P. C., Stern, S. A., and Sandel, B.: Nightglow in the upper atmosphere of Mars and implications for atmospheric transport, Science, 307, 566-569, doi:10.1126/science.1106957, 2005.

Bertaux, J. L., Gondet, B., Lefèvre, F., Bibring, J. P., and Montmessin, F.: First detection of $\mathrm{O}_{2} 1.27 \mu \mathrm{m}$ nightglow emission at Mars with OMEGA/MEX and comparison with general circulation model predictions, J. Geophys. Res., 117, E00J04, doi:10.1029/2011JE003890, 2012.

Boone, C. D., Nassar, R., Walker, K. A., Rochon, Y., McLeod, S. D., Rinsland, C. P., and Bernath, P. F.: Retrievals for the atmospheric chemistry experiment Fourier-transform spectrometer, Appl. Optics, 44, 7218-7231, doi:10.1364/AO.44.007218, 2005.
Boone, C. D., Walker, K. A., and Bernath, P. F.: Version 3 retrievals for the Atmospheric Chemistry Experiment Fourier Transform Spectrometer (ACE-FTS), in: ACE at 10: Solar Occultation Anthology, edited by: Bernath, P. F., A. Deepak Publishing, Hampton, VA, USA, 103-127, 2013.

Carlotti, M.: Global-fit approach to the analysis of limbscanning atmospheric measurements, Appl. Opt., 27, 32503254, doi:10.1364/AO.27.003250, 1988.

Clancy, R. T., Wolff, M. J., and Christensen, P. R.: Mars aerosol studies with the MGS TES emission phase function observations: optical depths, particle sizes, and ice cloud types versus latitude and solar longitude, J. Geophys. Res., 108, 5098, doi:10.1029/2003JE002058, 2003.

Clancy, R. T., Sandor, B. J., and Moriarty-Schieven, G. H.: A measurement of the $362 \mathrm{GHz}$ absorption line of Mars atmospheric $\mathrm{H}_{2} \mathrm{O}_{2}$, Icarus, 168, 116-121, doi:10.1016/j.icarus.2003.12.003, 2004.

Clancy, R. T., Sandor, B. J., Wolff, M. J., Smith, M. D., Lefèvre, F., Madeleine, J.-B., Forget, F., Murchie, S. L., Seelos, F. P., Seelos, K. D., Nair, H. A., Toigo, A. D., Humm, D., Kass, D. M., Kleinböhl, A., and Heavens, N.: Extensive MRO CRISM observations of $1.27 \mu \mathrm{m} \mathrm{O} \mathrm{O}_{2}$ airglow in Mars polar night and their comparison to MRO MCS temperature profiles and LMD GCM simulations, J. Geophys. Res., 117, E00J10, doi:10.1029/2011JE004018, 2012.

Clancy, R. T., Sandor, B. J., García-Muñoz, A., Lefèvre, F., Smith, M. D., Wolff, M. J., Montmessin, F., Murchie, S. L., and Nair, H.: First detection of Mars atmospheric hydroxyl: CRISM Near-IR measurement versus LMD GCM simulation of $\mathrm{OH}$ Meinel band emission in the Mars polar winter atmosphere, Icarus, 226, 272-281, doi:10.1016/j.icarus.2013.05.035, 2013.

Das, U. and Pan, C. J.: Validation of FORMOSAT-3/COSMIC level 2 "atmPrf" global temperature data in the stratosphere, Atmos. Meas. Tech., 7, 731-742, doi:10.5194/amt-7-731-2014, 2014.

Encrenaz, T., Greathouse, T. K., Richter, M. J., Lacy, J. H., Fouchet, T., Bézard, B., Lefèvre, F., Forget, F., and Atreya, S. K.: A stringent upper limit to $\mathrm{SO}_{2}$ in the Martian atmosphere, Astron. Astrophys., 530, A37, doi:10.1051/0004-6361/201116820, 2011.

Encrenaz, T., Greathouse, T. K., Lefèvre, F., and Atreya, S. K.: Hydrogen peroxide on Mars: observations, interpretation and future plans, Planet. Space Sci., 68, 3-17, doi:10.1016/j.pss.2011.03.019, 2012.

Fedorova, A. A., Korablev, O. I., Bertaux, J.-L., Rodin, A. V., Montmessin, F., Belyaev, D. A., and Reberac, A.: Solar infrared occultation observations by SPICAM experiment on Mars-Express: simultaneous measurements of the vertical distributions of $\mathrm{H}_{2} \mathrm{O}, \mathrm{CO}_{2}$ and aerosol, Icarus, 200, 96-117, doi:10.1016/j.icarus.2008.11.006, 2009.

Foelsche, U., Scherllin-Pirscher, B., Ladstädter, F., Steiner, A. K., and Kirchengast, G.: Refractivity and temperature climate records from multiple radio occultation satellites consistent within $0.05 \%$, Atmos. Meas. Tech., 4, 2007-2018, doi:10.5194/amt-4-2007-2011, 2011.

Fonti, S. and Marzo, G. A.: Mapping the methane on Mars, Astron. Astrophys., 512, A51, doi:10.1051/0004-6361/200913178, 2010.

Forget, F., Hourdin, F., Fournier, R., Hourdin, C., Talagrand, O., Collins, M., Lewis, S. R., Read, P. L., and Huot, J.-P.: Improved 
general circulation models of the Martian atmosphere from the surface to above $80 \mathrm{~km}$, J. Geophys. Res., 104, 24155-24176, doi:10.1029/1999JE001025, 1999.

Forget, F., Montmessin, F., Bertaux, J.-L., González-Galindo, F., Lebonnois, S., Quémerais, E., Reberac, A., Dimarellis, E., and López-Valverde, M. A.: Density and temperatures of the upper Martian atmosphere measured by stellar occultations with Mars Express SPICAM, J. Geophys. Res., 114, E01004, doi:10.1029/2008JE003086, 2009.

Formisano, V., Atreya, S., Encrenaz, T., Ignatiev, N., and Giuranna, M.: Detection of methane in the atmosphere of Mars, Science, 306, 1758-1761, doi:10.1126/science.1101732, 2004.

Gagné, M.-E., Bertaux, J.-L., González-Galindo, F., Melo, S. M. L., Montmessin, F., and Strong, K.: New nitric oxide (NO) nightglow measurements with SPICAM/MEx as a tracer of Mars upper atmosphere circulation and comparison with LMD-MGCM model prediction: evidence for asymmetric hemispheres, J. Geophys. Res., 118, 2172-2179, doi:10.1002/jgre.20165, 2013.

García-Comas, M., Funke, B., López-Puertas, M., BermejoPantaleón, D., Glatthor, N., von Clarmann, T., Stiller, G., Grabowski, U., Boone, C. D., French, W. J. R., Leblanc, T., López-González, M. J., and Schwartz, M. J.: On the quality of MIPAS kinetic temperature in the middle atmosphere, Atmos. Chem. Phys., 12, 6009-6039, doi:10.5194/acp-12-6009-2012, 2012.

García-Comas, M., Funke, B., Gardini, A., López-Puertas, M., Jurado-Navarro, A., von Clarmann, T., Stiller, G., Kiefer, M., Boone, C. D., Leblanc, T., Marshall, B. T., Schwartz, M. J., and Sheese, P. E.: MIPAS temperature from the stratosphere to the lower thermosphere: Comparison of vM21 with ACE-FTS, MLS, OSIRIS, SABER, SOFIE and lidar measurements, Atmos. Meas. Tech., 7, 3633-3651, doi:10.5194/amt-7-3633-2014, 2014.

Geminale, A., Formisano, V., and Sindoni, G.: Mapping methane in Martian atmosphere with PFS-MEX data, Planet. Space Sci., 59, 137-148, doi:10.1016/j.pss.2010.07.011, 2011.

Gille, J., Barnett, J., Arter, P., Barker, M., Bernath, P., Boone, C., Cavanaugh, C., Chow, J., Coffey, M., Craft, J., Craig, C., Dials, M., Dean, V., Eden, T., Edwards, D. P., Francis, G., Halvorson, C., Harvey, L., Hepplewhite, C., Khosravi, R., Kinnison, D., Krinsky, C., Lambert, A., Lee, H., Lyjak, L., Loh, J., Mankin, W., Massie, S., McInerney, J., Moorhouse, J., Nardi, B., Packman, D., Randall, C., Reburn, J., Rudolf, W., Schwartz, M., Serafin, J., Stone, K., Torpy, B., Walker, K., Waterfall, A., Watkins, R., Whitney, J., Woodard, D., and Young, G.: High Resolution Dynamics Limb Sounder: experiment overview, recovery, and validation of initial temperature data, J. Geophys. Res., 113, D16S43, doi:10.1029/2007JD008824, 2008.

Glavin, D. P., Freissinet, C., Miller, K. E., Eigenbrode, J. L., Brunner, A. E., Buch, A., Sutter, B., Archer, P. D., Atreya, S. K., Brinckerhoff, W. B., Cabane, M., Coll, P., Conrad, P. G., Coscia, D., Dworkin, J. P., Franz, H. B., Grotzinger, J. P., Leshin, L. A., Martin, M. G., McKay, C., Ming, D. W., NavarroGonzález, R., Pavlov, A., Steele, A., Summons, R. E., Szopa, C., Teinturier, S., and Mahaffy, P. R.: Evidence for perchlorates and the origin of chlorinated hydrocarbons detected by SAM at the Rocknest aeolian deposit in Gale Crater, J. Geophys. Res., 118, 1955-1973, doi:10.1002/jgre.20144, 2013.
Goldman, A., Paton-Walsh, C., Bell, W., Toon, G. C., Blavier, J.F., Sen, B., Coffey, M. T., Hannigan, J. W., and Mankin, W. G.: Network for the detection of stratospheric change Fourier transform infrared intercomparison at table mountain facility, November 1996, J. Geophys. Res., 104, 30481-30503, doi:10.1029/1999JD900879, 1999.

Hartogh, P., Błecka, M. I., Jarchow, C., Sagawa, H., Lellouch, E., de Val-Borro, M., Rengel, M., Medvedev, A. S., Swinyard, B. M., Moreno, R., Cavalié, T., Lis, D. C., Banaszkiewicz, M., Bockelée-Morvan, D., Crovisier, J., Encrenaz, T., Küppers, M., Lara, L.-M., Szutowicz, S., Vandenbussche, B., Bensch, F., Bergin, E. A., Billebaud, F., Biver, N., Blake, G. A., Blommaert, J. A. D. L., Cernicharo, J., Decin, L., Encrenaz, P., Feuchtgruber, H., Fulton, T., de Graauw, T., Jehin, E., Kidger, M., Lorente, R., Naylor, D. A., Portyankina, G., Sánchez-Portal, M., Schieder, R., Sidher, S., Thomas, N., Verdugo, E., Waelkens, C., Lorenzani, A., Tofani, G., Natale, E., Pearson, J., Klein, T., Leinz, C., Güsten, R., and Kramer, C.: First results on Martian carbon monoxide from Herschel/HIFI observations, Astron. Astrophys., 521, L48, doi:10.1051/0004-6361/201015159, 2010a.

Hartogh, P., Jarchow, C., Lellouch, E., de Val-Borro, M., Rengel, M., Moreno, R., Medvedev, A. S., Sagawa, H., Swinyard, B. M., Cavalié, T., Lis, D. C., Błęcka, M. I., Banaszkiewicz, M., Bockelée-Morvan, D., Crovisier, J., Encrenaz, T., Küppers, M., Lara, L.-M., Szutowicz, S., Vandenbussche, B., Bensch, F., Bergin, E. A., Billebaud, F., Biver, N., Blake, G. A., Blommaert, J. A. D. L., Cernicharo, J., Decin, L., Encrenaz, P., Feuchtgruber, H., Fulton, T., de Graauw, T., Jehin, E., Kidger, M., Lorente, R., Naylor, D. A., Portyankina, G., Sánchez-Portal, M., Schieder, R., Sidher, S., Thomas, N., Verdugo, E., Waelkens, C., Whyborn, N., Teyssier, D., Helmich, F., Roelfsema, P., Stutzki, J., Leduc, H. G., and Stern, J. A.: Herschel/HIFI observations of Mars: first detection of $\mathrm{O}_{2}$ at submillimetre wavelengths and upper limits on $\mathrm{HCl}$ and $\mathrm{H}_{2} \mathrm{O}_{2}$, Astron. Astrophys., 521, L49, doi:10.1051/0004-6361/201015160, 2010b.

Heavens, N. G., Richardson, M. I., Kleinböhl, A., Kass, D. M., McCleese, D. J., Abdou, W., Benson, J. L., Schofield, J. T., Shirley, J. H., and Wolkenberg, P. M.: Vertical distribution of dust in the Martian atmosphere during northern spring and summer: High-altitude tropical dust maximum at northern summer solstice, J. Geophys. Res., 116, E01007, doi:10.1029/2010JE003692, 2011.

Hecht, M. H., Kounaves, S. P., Quinn, R. C., West, S. J., Young, S. M. M., Ming, D. W., Catling, D. C., Clark, B. C., Boynton, W. V., Hoffman, J., DeFlores, L. P., Gospodinova, K., Kapit, J., and Smith, P. H.: Detection of perchlorate and the soluble chemistry of Martian soil at the Phoenix Lander Site, Science, 325, 64-67, doi:10.1126/science.1172466, 2009.

Hinson, D. P., Smith, M. D., and Conrath, B. J.: Comparison of atmospheric temperatures obtained through infrared sounding and radio occultation by Mars Global Surveyor, J. Geophys. Res., 109, E12002, doi:10.1029/2004JE002344, 2004.

Irion, F. W., Gunson, M. R., Toon, G. C., Chang, A. Y., Eldering, A., Mahieu, E., Manney, G. L., Michelsen, H. A., Moyer, E. J., Newchurch, M. J., Osterman, G. B., Rinsland, C. P., Salawitch, R. J., Sen, B., Yung, Y. L., and Zander, R.: Atmospheric Trace Molecule Spectroscopy (ATMOS) 
experiment version 3 data retrievals, Appl. Optics, 41, 69686979, doi:10.1364/AO.41.006968, 2002.

Kalnay, E., Kanamitsu, M., Kistler, R., Collins, W., Deaven, D., Gandin, L., Iredell, M., Saha, S., White, G., Woollen, J., Zhu, Y., Leetmaa, A., Reynolds, B., Chelliah, M., Ebisuzaki, W., Higgins, W., Janowiak, J., Mo, K. C., Ropelewski, C., Wang, J., Jenne, R., and Joseph, D.: The NCEP/NCAR 40-Year Reanalysis Project, Bull. Am. Astron. Soc., 77, 437-472, doi:10.1175/15200477(1996)077<0437:TNYRP>2.0.CO;2, 1996.

Kerzenmacher, T. E., Walker, K. A., Strong, K., Berman, R., Bernath, P. F., Boone, C. D., Drummond, J. R., Fast, H., Fraser, A., MacQuarrie, K., Midwinter, C., Sung, K., McElroy, C. T., Mittermeier, R. L., Walker, J., and Wu, H.: Measurements of $\mathrm{O}_{3}, \mathrm{NO}_{2}$ and temperature during the 2004 Canadian Arctic ACE Validation Campaign, Geophys. Res. Lett., 32, L16S07, doi:10.1029/2005GL023032, 2005.

Kishore, P., Namboothiri, S. P., Jiang, J. H., Sivakumar, V., and Igarashi, K.: Global temperature estimates in the troposphere and stratosphere: a validation study of COSMIC/FORMOSAT-3 measurements, Atmos. Chem. Phys., 9, 897-908, doi:10.5194/acp-9-897-2009, 2009.

Kleinböhl, A., Schofield, J. T., Kass, D. M., Abdou, W. A., Backus, C. R., Sen, B., Shirley, J. H., Lawson, W. G., Richardson, M. I., Taylor, F. W., Teanby, N. A., and McCleese, D. J.: Mars Climate Sounder limb profile retrieval of atmospheric temperature, pressure, and dust and water ice opacity, J. Geophys. Res., 114, E10006, doi:10.1029/2009JE003358, 2009.

Korablev, O., Trokhimovsky, A., Grigoriev, A. V., Shakun, A., Ivanov, Y. S., Moshkin, B., Anufreychik, K., Timonin, D., Dziuban, I., Kalinnikov, Y. K., and Montmessin, F.: Three infrared spectrometers, an atmospheric chemistry suite for the ExoMars 2016 trace gas orbiter, J. Appl. Remote Sens., 8, 084983 , doi:10.1117/1.JRS.8.084983, 2014.

Krasnopolsky, V. A.: Long-term spectroscopic observations of Mars using IRTF/CSHELL: Mapping of $\mathrm{O}_{2}$ dayglow, $\mathrm{CO}$, and search for $\mathrm{CH}_{4}$, Icarus, 190, 93-102, doi:10.1016/j.icarus.2007.02.014, 2007.

Krasnopolsky, V. A.: Search for methane and upper limits to ethane and $\mathrm{SO}_{2}$ on Mars, Icarus, 217, 144-152, doi:10.1016/j.icarus.2011.10.019, 2012.

Krasnopolsky, V. A. and Feldman, P. D.: Detection of molecular hydrogen in the atmosphere of Mars, Science, 294, 1914-1917, doi:10.1126/science.1065569, 2001.

Krasnopolsky, V. A., Maillard, J. P., and Owen, T. C.: Detection of methane in the Martian atmosphere: evidence for life?, Icarus, 172, 537-547, doi:10.1016/j.icarus.2004.07.004, 2004.

Lebonnois, S., Quémerais, E., Montmessin, F., Lefèvre, F., Perrier, S., Bertaux, J.-L., and Forget, F.: Vertical distribution of ozone on Mars as measured by SPICAM/Mars Express using stellar occultations, J. Geophys. Res., 111, E09S05, doi:10.1029/2005JE002643, 2006.

Lefèvre, F. and Forget, F.: Observed variations of methane on Mars unexplained by known atmospheric chemistry and physics, Nature, 460, 720-723, doi:10.1038/nature08228, 2009.

Määttänen, A., Listowski, C., Montmessin, F., Maltagliati, L., Reberac, A., Joly, L., and Bertaux, J.-L.: A complete climatology of the aerosol vertical distribution on Mars from MEx/SPICAM UV solar occultations, Icarus, 223, 892-941, doi:10.1016/j.icarus.2012.12.001, 2013.
Mahaffy, P. R., Webster, C. R., Atreya, S. K., Franz, H., Wong, M., Conrad, P. G., Harpold, D., Jones, J. J., Leshin, L. A., Manning, H., Owen, T., Pepin, R. O., Squyres, S., Trainer, M., and the MSL Science Team: Abundance and isotopic composition of gases in the Martian atmosphere from the Curiosity Rover, Science, 341, 263-266, doi:10.1126/science.1237966, 2013.

Maltagliati, L., Montmessin, F., Fedorova, A., Korablev, O., Forget, F., and Bertaux, J.-L.: Evidence of water vapor in excess of saturation in the atmosphere of Mars, Science, 333, 1868-1871, doi:10.1126/science.1207957, 2011.

Maltagliati, L., Montmessin, F., Korablev, O., Fedorova, A., Forget, F., Määttänen, A., Lefèvre, F., and Bertaux, J.-L.: Annual survey of water vapor vertical distribution and water-aerosol coupling in the martian atmosphere observed by SPICAM/MEx solar occultations, Icarus, 223, 942-962, 2013.

Mamun, A., Kaminski, J., Lupu, A., Semeniuk, K., and McConnell, J. C.: Evaluation of stratospheric temperature and water vapor from GEM using ACE-FTS and MLS measurements, in: ACE at 10: Solar Occultation Anthology, edited by: Bernath, P. F., A. DEEPAK Publishing, Hampton, VA, USA, 295-302, 2013.

Manney, G. L., Daffer, W. H., Strawbridge, K. B., Walker, K. A., Boone, C. D., Bernath, P. F., Kerzenmacher, T., Schwartz, M. J., Strong, K., Sica, R. J., Krüger, K., Pumphrey, H. C., Lambert, A., Santee, M. L., Livesey, N. J., Remsberg, E. E., Mlynczak, M. G., and Russell III, J. R.: The high Arctic in extreme winters: vortex, temperature, and MLS and ACE-FTS trace gas evolution, Atmos. Chem. Phys., 8, 505-522, doi:10.5194/acp-8-505-2008, 2008.

Marshall, B. T., Deaver, L. E., Thompson, R. E., Gordley, L. L., McHugh, M. J., Hervig, M. E., and Russell III, J. M.: Retrieval of temperature and pressure using broadband solar occultation: SOFIE approach and results, Atmos. Meas. Tech., 4, 893-907, doi:10.5194/amt-4-893-2011, 2011.

Mumma, M. J., Villanueva, G. L., Novak, R. E., Hewagama, T., Bonev, B. P., DiSanti, M. A., Mandell, A. M., and Smith, M. D.: Strong release of methane on Mars in northern summer 2003, Science, 323, 1041-1045, doi:10.1126/science.1165243, 2009.

Norton, R. H. and Rinsland, C. P.: ATMOS data processing and science analysis methods, Appl. Optics, 30, 389-400, doi:10.1364/AO.30.000389, 1991.

Nowlan, C. R., Drummond, J. R., McElroy, C. T., and Barton, D. V.: Solar occultation measurements of atmospheric pressure and temperature from the A- and B-bands of molecular oxygen, in: ACE at 10: Solar Occultation Anthology, edited by: Bernath, P. F., A. DEEPAK Publishing, Hampton, Virg., 261270, 2013.

Owen, T., Biemann, K., Biller, J. E., Lafleur, A. L., Rushneck, D. R., and Howarth, D. W.: The composition of the atmosphere at the surface of Mars, J. Geophys. Res., 82, 4635-4639, doi:10.1029/JS082i028p04635, 1977.

Picone, J. M., Hedin, A. E., Drob, D. P., and Aikin, A. C.: NRLMSISE-00 empirical model of the atmosphere: Statistical comparisons and scientific issues, J. Geophys. Res., 107, 1486, doi:10.1029/2002JA009430, 2002.

Rothman, L. S., Hawkins, R. L., Wattson, R. B., and Gamache, R. R.: Energy levels, intensities, and linewidths of atmospheric carbon dioxide bands, J. Quant. Spectrosc. Ra., 48, 537-566, doi:10.1016/0022-4073(92)90119-O, 1992. 
Rothman, L. S., Rinsland, C. P., Goldman, A., Massie, S. T., Edwards, D. P., Flaud, J.-M., Perrin, A., Camy-Peyret, C., Dana, V., Mandin, J.-Y., Schroeder, J., Mccann, A., Gamache, R. R., Wattson, R. B., Yoshino, K., Chance, K. V., Jucks, K. W., Brown, L. R., Namtchinov, V., and Varanasi, P.: The HITRAN Molecular Spectroscopic Database and HAWKS (HITRAN Atmospheric Workstation): 1996 edition, J. Quant. Spectrosc. Ra., 60, 665-710, doi:10.1016/S0022-4073(98)00078-8, 1998.

Rothman, L. S., Gordon, I. E., Babikov, Y., Barbe, A., Chris Benner, D., Bernath, P. F., Birk, M., Bizzocchi, L., Boudon, V., Brown, L. R., Campargue, A., Chance, K., Cohen, E. A., Coudert, L. H., Devi, V. M., Drouin, B. J., Fayt, A., Flaud, J.M., Gamache, R. R., Harrison, J. J., Hartmann, J.-M., Hill, C., Hodges, J. T., Jacquemart, D., Jolly, A., Lamouroux, J., Le Roy, R. J., Li, G., Long, D. A., Lyulin, O. M., Mackie, C. J., Massie, S. T., Mikhailenko, S., Müller, H. S. P., Naumenko, O. V., Nikitin, A. V., Orphal, J., Perevalov, V., Perrin, A., Polovtseva, E. R., Richard, C., Smith, M. A. H., Starikova, E., Sung, K., Tashkun, S., Tennyson, J., Toon, G. C., Tyuterev, V. G., and Wagner, G.: The HITRAN2012 molecular spectroscopic database, J. Quant. Spectrosc. Ra., 130, 4-50, doi:10.1016/j.jqstr.2013.07.002, 2013.

Schreiner, W., Rocken, C., Sokolovskiy, S., Syndergaard, S., and Hunt, D.: Estimates of the precision of GPS radio occultations from the COSMIC/FORMOSAT-3 mission, Geophys. Res. Lett., 34, L04808, doi:10.1029/2006GL027557, 2007.

Schwartz, M. J., Lambert, A., Manney, G. L., Read, W. G., Livesey, N. J., Froidevaux, L., Ao, C. O., Bernath, P. F., Boone, C. D., Cofield, R. E., Daffer, W. H., Drouin, B. J., Fetzer, E. J., Fuller, R. A., Jarnot, R. F., Jiang, J. H., Jiang, Y. B., Knosp, B. W., Krüger, K., Li, J.-L. F., Mlynczak, M. G., Pawson, S., Russell, J. M., Santee, M. L., Snyder, W. V., Stek, P. C., Thurstans, R. P., Tompkins, A. M., Wagner, P. A., Walker, K. A., Waters, J. W., and Wu, D. L.: Validation of the Aura Microwave Limb Sounder temperature and geopotential height measurements, J. Geophys. Res., 113, D15S11, doi:10.1029/2007JD008783, 2008.

Sheese, P. E., Strong, K., Llewellyn, E. J., Gattinger, R. L., Russell III, J. M., Boone, C. D., Hervig, M. E., Sica, R. J., and Bandoro, J.: Assessment of the quality of OSIRIS mesospheric temperatures using satellite and ground-based measurements, Atmos. Meas. Tech., 5, 2993-3006, doi:10.5194/amt-5-2993-2012, 2012

Sica, R. J., Izawa, M. R. M., Walker, K. A., Boone, C., Petelina, S. V., Argall, P. S., Bernath, P., Burns, G. B., Catoire, V., Collins, R. L., Daffer, W. H., De Clercq, C., Fan, Z. Y., Firanski, B. J., French, W. J. R., Gerard, P., Gerding, M., Granville, J., Innis, J. L., Keckhut, P., Kerzenmacher, T., Klekociuk, A. R., Kyrö, E., Lambert, J. C., Llewellyn, E. J., Manney, G. L., McDermid, I. S., Mizutani, K., Murayama, Y., Piccolo, C., Raspollini, P., Ridolfi, M., Robert, C., Steinbrecht, W., Strawbridge, K. B., Strong, K., Stübi, R., and Thurairajah, B.: Validation of the Atmospheric Chemistry Experiment (ACE) version 2.2 temperature using ground-based and space-borne measurements, Atmos. Chem. Phys., 8, 35-62, doi:10.5194/acp-8-35-2008, 2008.

Sindoni, G., Formisano, V., and Geminale, A.: Observations of water vapour and carbon monoxide in the Martian atmosphere with the SWC of PFS/MEX, Planet. Space Sci., 59, 149-162, doi:10.1016/j.pss.2010.12.006, 2011.
Stevens, M. H., Deaver, L. E., Hervig, M. E., Russell, III, J. M., Siskind, D. E., Sheese, P. E., Llewellyn, E. J., Gattinger, R. L., Höffner, J., and Marshall, B. T.: Validation of upper mesospheric and lower thermospheric temperatures measured by the Solar Occultation for Ice Experiment, J. Geophys. Res., 117, D16304, doi:10.1029/2012JD017689, 2012.

Stiller, G. P., Gunson, M. R., Lowes, L. L., Abrams, M. C., Raper, O. F., Farmer, C. B., Zander, R., and Rinsland, C. P. Stratospheric and mesospheric pressure-temperature profiles from rotational analysis of $\mathrm{CO}_{2}$ lines in Atmospheric Trace Molecule Spectroscopy/ATLAS 1 infrared solar occultation spectra, J. Geophys. Res., 100, 3107-3118, doi:10.1029/94JD03105, 1995.

Stiller, G. P., Kiefer, M., Eckert, E., von Clarmann, T., Kellmann, S., García-Comas, M., Funke, B., Leblanc, T., Fetzer, E., Froidevaux, L., Gomez, M., Hall, E., Hurst, D., Jordan, A., Kämpfer, N., Lambert, A., McDermid, I. S., McGee, T., Miloshevich, L., Nedoluha, G., Read, W., Schneider, M., Schwartz, M., Straub, C., Toon, G., Twigg, L. W., Walker, K., and Whiteman, D. N.: Validation of MIPAS IMK/IAA temperature, water vapor, and ozone profiles with MOHAVE-2009 campaign measurements, Atmos. Meas. Tech., 5, 289-320, doi:10.5194/amt-5-289-2012, 2012.

Summers, M. E., Lieb, B. J., Chapman, E., and Yung, Y. L.: Atmospheric biomarkers of subsurface life on Mars, Geophys. Res. Lett., 29, 2171, doi:10.1029/2002GL015377, 2002.

Sun, B., Reale, A., Seidel, D. J., and Hunt, D. C.: Comparing radiosonde and COSMIC atmospheric profile data to quantify differences among radiosonde types and the effects of imperfect collocation on comparison statistics, J. Geophys. Res., 115, D23104, doi:10.1029/2010JD014457, 2010.

Toon, G. C.: The JPL MkIV interferometer, Opt. Photonics News, 2, 19-21, doi:10.1364/OPN.2.10.000019, 1991.

Villanueva, G. L., Mumma, M. J., Novak, R. E., Radeva, Y. L., Käufl, H. U., Smette, A., Tokunaga, A., Khayat, A., Encrenaz, T., and Hartogh, P.: A sensitive search for organics $\left(\mathrm{CH}_{4}, \mathrm{CH}_{3} \mathrm{OH}, \mathrm{H}_{2} \mathrm{CO}, \mathrm{C}_{2} \mathrm{H}_{6}, \mathrm{C}_{2} \mathrm{H}_{2}, \mathrm{C}_{2} \mathrm{H}_{4}\right)$, hydroperoxyl $\left(\mathrm{HO}_{2}\right)$, nitrogen compounds $\left(\mathrm{N}_{2} \mathrm{O}, \mathrm{NH}_{3}, \mathrm{HCN}\right)$ and chlorine species $\left(\mathrm{HCl}, \mathrm{CH}_{3} \mathrm{Cl}\right)$ on Mars using groundbased high-resolution infrared spectroscopy, Icarus, 223, 11-27, doi:10.1016/j.icarus.2012.11.013, 2013.

Wang, J., Hock, T., Cohn, S. A., Martin, C., Potts, N., Reale, T., Sun, B., and Tilley, F.: Unprecedented upper-air dropsonde observations over Antarctica from the 2010 Concordiasi Experiment: validation of satellite-retrieved temperature profiles, Geophys. Res. Lett., 40, 1231-1236, doi:10.1002/grl.50246, 2013.

Wang, K.-Y. and Lin, S.-C.: First continuous GPS soundings of temperature structure over Antarctic winter from FORMOSAT3/COSMIC constellation, Geophys. Res. Lett., 34, L12805, doi:10.1029/2007GL030159, 2007.

Webster, C. R., Mahaffy, P. R., Atreya, S. K., Flesch, G. J., Farley, K. A., Kemppinen, O., Bridges, N., Johnson, J. R., Minitti, M., Cremers, D., and the MSL Science Team: Low upper limit to methane abundance on Mars, Science, 342, 355-357, doi:10.1126/science.1242902, 2013.

Webster, C. R., Mahaffy, P. R., Atreya, S. K., Flesch, G. J., Mischna, M. A., Meslin, P.-V., Farley, K. A., Kemppinen, O., Conrad, P. G., Christenson, L. E., Pavlov, A. A., Martín-Torres, J., Zorzano, M.-P., McConnochie, T. H., and the MSL Science 
Team: Mars methane detection and variability at Gale crater, Science, 347, 415-417, doi:10.1126/science.1261713, 2015.

Wong, A.-S., Atreya, S. K., and Encrenaz, T.: Chemical markers of possible hot spots on Mars, J. Geophys. Res., 108, 5026, doi:10.1029/2002JE002003, 2003.

Wunch, D., Toon, G. C., Blavier, J. L., Washenfelder, R. A., Notholt, J., Connor, B. J., Griffith, D. W. T., Sherlock, V., and Wennberg, P. O.: The Total Carbon Column Observing Network, Philos. T. R. Soc. A, 369, 2087-2112, doi:10.1098/rsta.2010.0240, 2011.
Zahnle, K., Freedman, R. S., and Catling, D. C.: Is there methane on Mars?, Icarus, 212, 493-503, doi:10.1016/j.icarus.2010.11.027, 2011.

Zhang, K., Fu, E., Silcock, D., Wang, Y., and Kuleshov, Y.: An investigation of atmospheric temperature profiles in the Australian region using collocated GPS radio occultation and radiosonde data, Atmos. Meas. Tech., 4, 2087-2092, doi:10.5194/amt-42087-2011, 2011. 